\title{
Identification of Pathogenesis-Associated Genes by T-DNA-Mediated Insertional Mutagenesis in Botrytis cinerea: A Type 2A Phosphoprotein Phosphatase and an SPT3 Transcription Factor Have Significant Impact on Virulence
}

\author{
S. Giesbert, ${ }^{1}$ J. Schumacher, ${ }^{1}$ V. Kupas, ${ }^{1}$ J. Espino, ${ }^{1}$ N. Segmüller, ${ }^{1}$ I. Haeuser-Hahn, ${ }^{2}$ P. H. Schreier, ${ }^{2}$ \\ and P. Tudzynski ${ }^{1}$ \\ ${ }^{1}$ Institut für Biologie und Biotechnologie der Pflanzen, Westf. Wilhelms-Universität, Hindenburgplatz 55, D-48143 Münster, \\ Germany; ' ${ }^{2}$ Bayer Crop Science AG, Alfred Nobel-Straße 50, D-40789 Monheim, Germany
}

Submitted 27 July 2011. Accepted 16 November 2011.

\begin{abstract}
Agrobacterium tumefaciens-mediated transformation (ATMT) was used to generate an insertional mutant library of the gray mold fungus Botrytis cinerea. From a total of 2,367 transformants, 68 mutants showing significant reduction in virulence on tomato and bean plants were analyzed in detail. As reported for other fungal ATMT libraries, integrations were mostly single copy, occurred preferentially in noncoding (regulatory) regions, and were frequently accompanied by small deletions of the target sequences and loss of parts of the border sequence. Two T-DNA integration events that were found to be linked to virulence were characterized in more detail: a catalytic subunit of a PP2A serine/threonine protein phosphatase (BcPP2Ac) and the SPT3 subunit of a Spt-Ada-Gcn5-acetyltransferase (SAGA-like) transcriptional regulator complex. Gene replacement and silencing approaches revealed that both Bcpp2Ac and SPT3 are crucial for virulence, growth, and differentiation as well as for resistance to $\mathrm{H}_{2} \mathrm{O}_{2}$ in $B$. cinerea.
\end{abstract}

\begin{abstract}
Botrytis cinerea, the gray mold fungus, is a broad-hostrange necrotrophic pathogen, which causes considerable economic damage in crop plants and ornamentals. Its complex virulence strategy has been studied intensively in recent years using molecular approaches (Tudzynski and Kokkelink 2009; van Kan 2006; Williamson et al. 2007). The availability of genomic resources (genome sequence and expressed sequence tag [EST] databases) and the relatively easy experimental access (e.g., high knock-out efficiency) has allowed a broad target gene approach for the identification of pathogenicityrelated genes. A recent review (Tudzynski and Kokkelink 2009) lists 102 mutants obtained by targeted inactivation of suspected virulence or pathogenicity genes, of which 31 were significantly impaired in virulence but only six were nonpathogenic. This revelation demonstrates the genetic complexity of the fungus, and the need for alternative approaches to identify pathogenicity-related genes. The preliminary evaluation of the
\end{abstract}

Corresponding author: P. Tudzynski; E-mail: tudzyns @uni-muenster.de

* The $\boldsymbol{e}$-Xtra logo stands for "electronic extra" and indicates that three supplementary figures and one supplementary table are published online. genome sequences showed that a large proportion of the predicted genes had no similarity to any other gene bank entry (Viaud et al. 2005). Because a genome-wide functional analysis as used in Neurospora crassa (Colot et al. 2006) is unrealistic at present, a forward genetic approach appears to be the best method to identify additional pathogenicity-related genes. As in other fungal pathogens, such as Leptosphaeria maculans (Blaise et al. 2007) and Magnaporthe grisea (Betts et al. 2007; Choi et al. 2007; Meng et al. 2007), Agrobacterium tumefaciens-mediated transformation (ATMT) has proven to be a valuable method to obtain insertional mutant libraries and to identify pathogenicity-related genes. Therefore, we initiated such an insertional mutagenesis approach in $B$. cinerea by use of the technique previously established for this species (Rolland et al. 2003; Tudzynski and Siewers 2004) to generate a library of 2,367 mutants and identify more than 100 mutants with significantly reduced virulence, 40 of which show complete loss of pathogenicity. We report here the general characteristics of a large set of these mutants and present a detailed examination of two new factors affecting virulence: a PP2A protein phosphatase and an SPT3 component of the Spt-Ada-Gcn5-acetyltransferase (SAGA) complex, both of which have never been considered as possibly linked to virulence in $B$. cinerea, thus demonstrating the usefulness of this approach.

\section{RESULTS}

Generation of a mutant library and virulence screen.

A collection of 2,367 hygromycin-resistant transformants was generated using an optimized ATMT protocol (differing in several aspects from that of Rolland and associates [2003]; discussed below). The transformants were genetically purified by one round of single-spore isolation and routinely checked by polymerase chain reaction (PCR) to confirm the integration of the hygromycin resistance cassette conveyed by the vector pAG1. Southern analysis of randomly chosen transformants indicated that most of the mutants contained single integrations of the T-DNA (though the occurrence of double insertions yielding by chance the same band sizes cannot be excluded). In addition, the different sizes of T-DNA-containing fragments indicated random integration (Supplementary Fig. S1).

All the transformants were prescreened in a detached tomato leaf virulence assay and classified according to the severity of 
the symptoms. In total, 102 mutants were nonpathogenic, 138 mutants were severely reduced in virulence, and 320 were only slightly affected, whereas 1,807 mutants showed wild-typelike infection patterns. Most mutants that were either nonpathogenic or severely impaired in virulence compared with the wild type were subjected to a second pathogenicity screen (some mutants turned out to be unstable and could not be recovered from storage). In this experiment, the pathogenicity tests were performed on whole bean plants because this assay is more sensitive and reproducible. Of 166 mutants tested, 40 were nonpathogenic (classified as type 1), 29 mutants developed primary lesions but showed no further lesion spread (classified as type 2), 56 developed a so-called "secondary lesion" but produced no or less conidia (classified as type 3), and 41 infected the bean plant in a wild-type manner (Fig. 1). Thus, of the 2,367 mutants entering the screen, $5 \%$ could be assigned to phenotypic categories 1 to 3 .

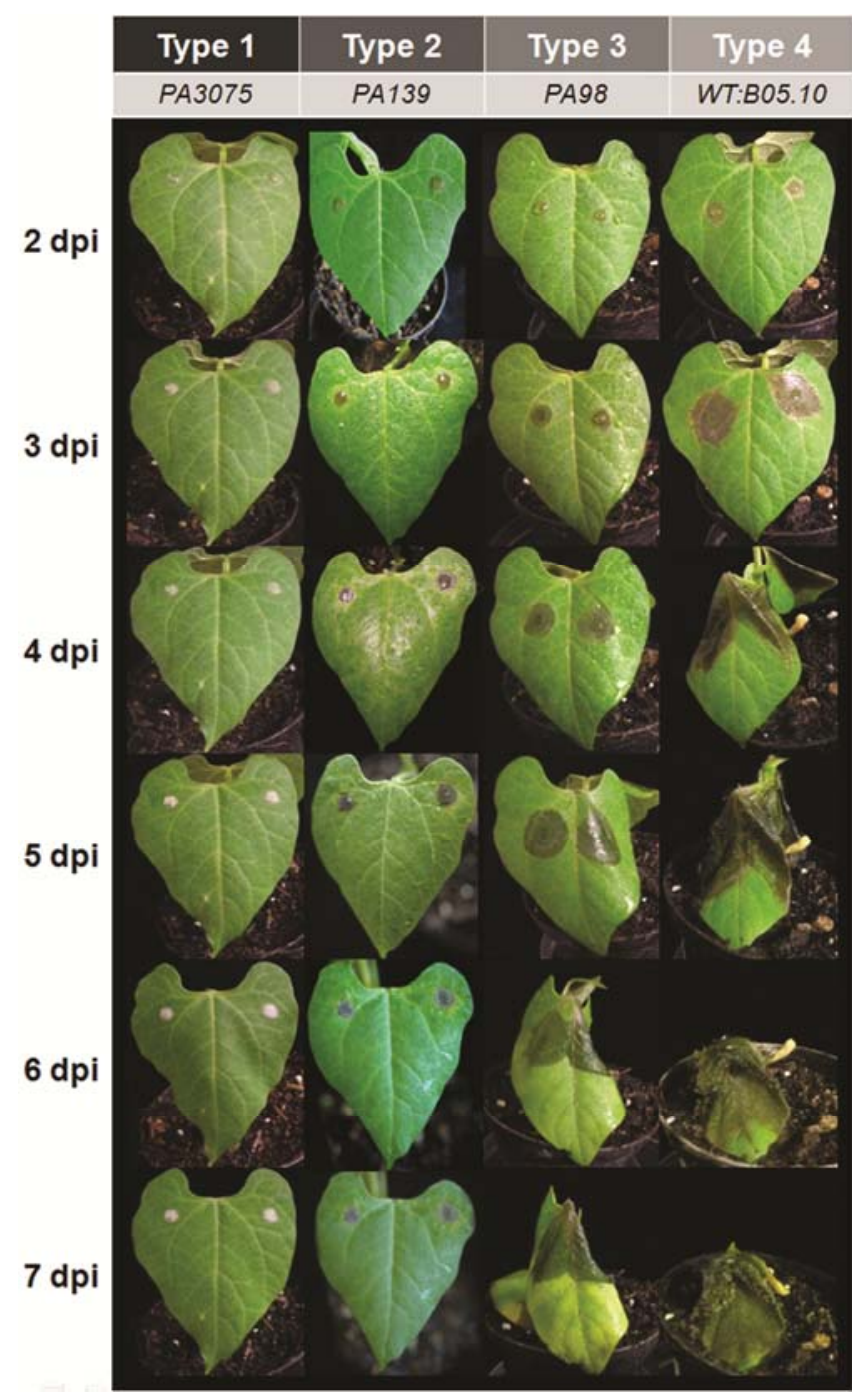

Fig. 1. Classification of virulence phenotypes of Agrobacterium tumefaciens-mediated transformation (ATMT) lines. Virulence was monitored for 1 week on primary bean leaves of French bean (Phaseolus vulgaris) using conidial suspensions as inoculum. Agar plugs with mycelia were used when ATMT lines failed to produce conidia. Phenotypes were classified in four groups: type 1 strains do not cause any visible disease symptoms, type 2 strains penetrate the host tissue and produce small necrotic lesion but without further invasive growth, type 3 strains are capable of invasive growth but infections are significantly retarded and conidiation is restricted or abolished, and type 4 strains show the wild-type infection pattern.

\section{Rescue of T-DNA flanking regions.}

Based on Southern analyses, 68 virulence-attenuated mutants that clearly showed a single integration event were subjected to a detailed molecular study. To isolate the genomic regions adjacent to the left and right borders of the T-DNA integration event, thermal asymmetrical interbred (TAIL)-PCR was performed in these transformants (discussed below). In 34 mutants, both flanks adjacent to the T-DNA could be amplified successfully whereas, in 10 transformants, only the right border (RB), and in 20 transformants, only the left border (LB), could be isolated. In four transformants, the attempt to isolate the T-DNA flanking regions remained unsuccessful for both flanks due to malfunction of TAIL-PCR as well as inverse PCR that had been used for those cases in which the TAIL-PCR failed. In summary, for $94 \%$ of the analyzed mutants, recovery of at least one border was successful.

\section{Analysis of T-DNA integration sites.}

In total, 98 border sequences (LB and RB) could be rescued successfully and were subsequently further analyzed to locate overlapping sequences with the vector used for the Agrobacterium transformation. Only sequences that showed an overlap (i.e., they were not equivalent with randomly obtained PCR products) were compared with the genomic databases of the recipient strain B05.10 as well as to the database of $B$. cinerea T4 that also includes EST data. The availability of both databases allowed a detailed analysis of the integration sites of the T-DNA. Among the 98 border sequences obtained, 13\% correspond to T-DNA or other non-T-DNA vector-derived sequences. Most of these were obtained during the attempt to rescue the LB sequence, probably indicating inefficiency during cutting the T-DNA when transferring the vector into the fungal genome, a phenomenon that has also been described by Meng and associates (2007).

Of the total 68 analyzed transformants, in five strains (7\%) the obtained sequences did not match adjacent genomic regions, probably due to a translocation or recombination event or two integration events on different chromosomes. In 22 transformants, both flanks corresponded to adjacent genomic regions. Of these, in $54 \%$, only small deletions of 2 to 20 bp were caused by the T-DNA integration. Nevertheless, greater deletions of 20 to $300 \mathrm{bp}$ also occurred and, in one case, complete loss of a $12.3-\mathrm{kb}$ region was observed. These data are consistent with observations made in other fungal ATMT systems (e.g., M. grisea) (Meng et al. 2007).

To analyze the site of the integration in relation to an open reading frame (ORF), we examined only those loci that were annotated as an ORF, either in the strain B05.10 BROAD annotation or in the B. cinerea T4 URGI annotation. Excluded from the calculations were those mutants for which only vector sequences could be isolated or those where the obtained LB and RB flanks were incompatible. Altogether, of 51 transformants,

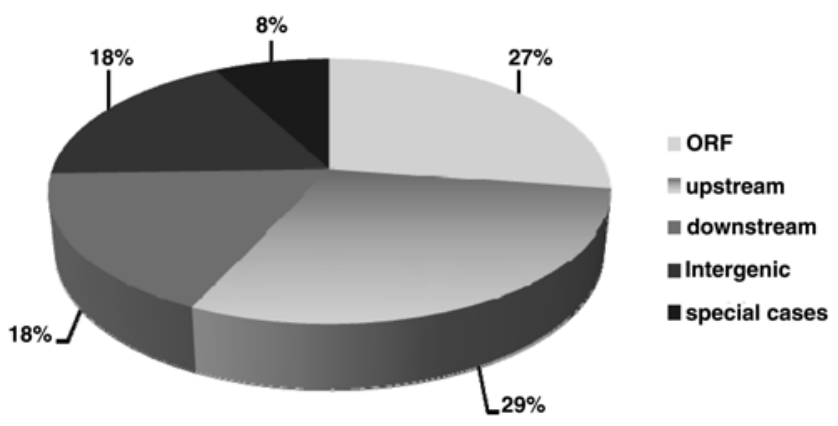

Fig. 2. Percentage distribution of the T-DNA integration sites in relation to an annotated open reading frame (ORF). 

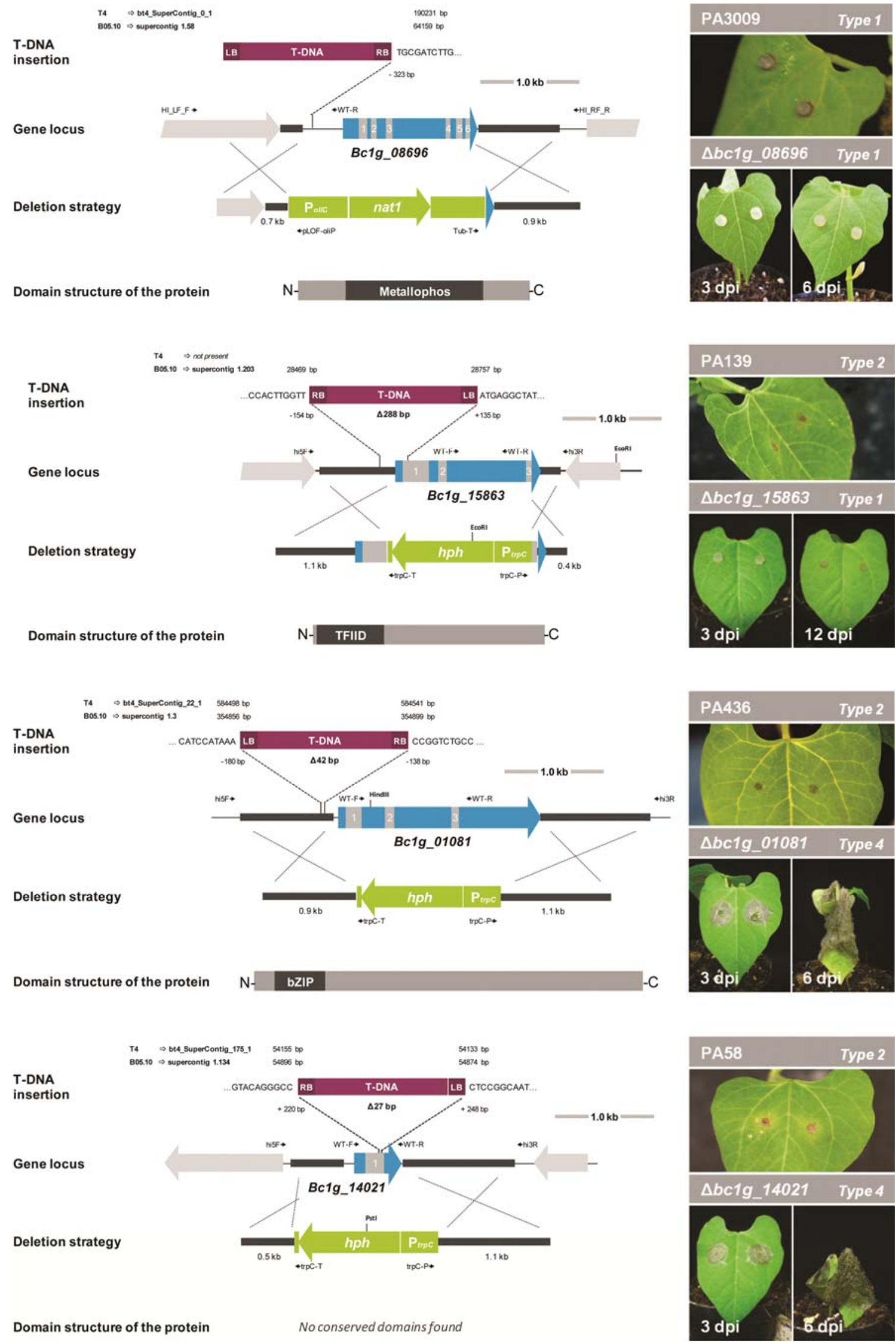

Fig. 3. Detailed analysis of four candidate genes identified by the Agrobacterium tumefaciens-mediated transformation (ATMT) approach. T-DNA insertion sites, the tagged open reading frames (ORFs), and the pursued deletion strategies are indicated. Conserved domains in the predicted proteins were identified using PFAM and are Metallophos, Calcineurin-like phosphoesterase; TFIID, transcription initiation factor IID, 18-kDa subunit; and bZIP, bZIP-like leucine zipper; dpi = days postinfection. Virulence phenotypes of ATMT lines and the generated deletion mutants on Phaseolus vulgaris are shown. Bcpp2Ac corresponds to annotated ORF bclg_08696 and bcspt3 to bclg_15863 in the B. cinerea B05.10 database. 
$14(27 \%)$ showed a T-DNA integration within an annotated ORF, $29 \%$ of the mutants had an integration in an upstream region of an ORF (up to 1,000 bp 5' of an ORF is regarded as "upstream"), $18 \%$ showed an integration downstream (within $1,000 \mathrm{bp} \mathrm{3'}$ ' of an annotated ORF), and, in $18 \%$ of the cases, the integration occurred in an intergenic region (more than 1,000 bp distant from an annotated ORF). In $8 \%$ of the cases, the transformants were classified as being "special cases" (e.g., an integration into a putative retrotransposon sequence or the locus is not annotated as an ORF but EST sequences map to the insertion site) (Fig. 2).

\section{Linking T-DNA integration to virulence.}

In total, 51 T-DNA integrations could be identified that are located intergenic, upstream, downstream, or within an ORF. It has to be considered, however, that most of these ORF had been annotated automatically. For many of them, corresponding EST sequences are present in the T4 database or they show high similarity to other proteins and, hence, might be regarded as bona fide genes. In 8 of the 51 identified integration sites, it is still not clear whether the tagged locus should be considered as a functional gene because there are either no EST matches of the relevant ORF or no similarity can be found to other genes.

None of the genes identified thus far correspond to any of the known $B$. cinerea virulence factors (Tudzynski and Kokkelink 2009). Nevertheless, some of them show similarity to genes that code for proteins involved in virulence in other fungi (e.g., SPT3-like transcription factor which is required for virulence in Candida albicans) (Laprade et al. 2002).

When categorizing all annotated unambiguously identified putative genes $(n=31)$ according to their known function, 10 can be linked to primary or secondary metabolism; seven can be classified as involved in signal transduction; two are involved in development and morphogenesis; two are in the category cellular transport, transport facilities, and transport routes; seven matched to hypothetical proteins of other filamentous fungi; whereas three genes seemed to be unique to the genome of $B$. cinerea or Sclerotinia sclerotiorum. Some examples of tagged genes are presented in Table 1 that possibly represent candidates for virulence factors in $B$. cinerea.

To verify whether the identified genes are, indeed, responsible for the observed phenotypes of the relevant ATMT mutants, either complementation of the mutant with a wild-type copy of the tagged region or a knock-out of the tagged gene in the wild-type strain could be performed to confirm the linkage of phenotype and T-DNA integration as described previously (Michielse et al. 2009). A broad functional analysis of the mutants using the second approach has been initiated (i.e., by performing gene replacement experiments). For these, only those mutants were included in which the T-DNA was integrated in an obvious (unambiguously identified) ORF that is most likely a transcribed gene or in close proximity to a gene. Reversetranscription (RT)-PCR experiments that were performed with the chosen candidates confirmed the transcription of the candidate gene in the wild type.

Here, the further characterization of four mutants (PA3009, PA139, PA58, and PA436) is presented that show T-DNA integrations in genes encoding different categories of proteins by use of different approaches to confirm the linkage between T-DNA integration and the observed phenotype (Fig. 3).

\section{PA3009.}

The first of the selected mutants, PA3009, has been classified as belonging to type 1 because of its inability to cause symptoms on bean leaves. It exhibits a slow growth rate in axenic culture on complete medium (CM) and minimal medium (CD) and does not produce any sclerotia when grown in the dark. As can be seen in Figure 3, the integration of T-DNA was found 348 bp downstream of bclg_08695 and 289 upstream of the predicted start codon of bclg_08696. BC1G_08695 shows high similarity to an exocyst complex component EXO84 of $N$. crassa $(E=0)$, whereas BC1G_08696 is predicted to encode a 328-amino-acid (aa) protein that exhibits high similarity to $N$. crassa serine/threonine protein phosphatase PP2A-2 catalytic subunit $(E=0)$. Because the T-DNA integration was found in the promoter region of bclg_08696, it seemed more likely that an altered expression of $b c 1 g \_08696$ was responsible for the phenotype of mutant PA3009 rather than

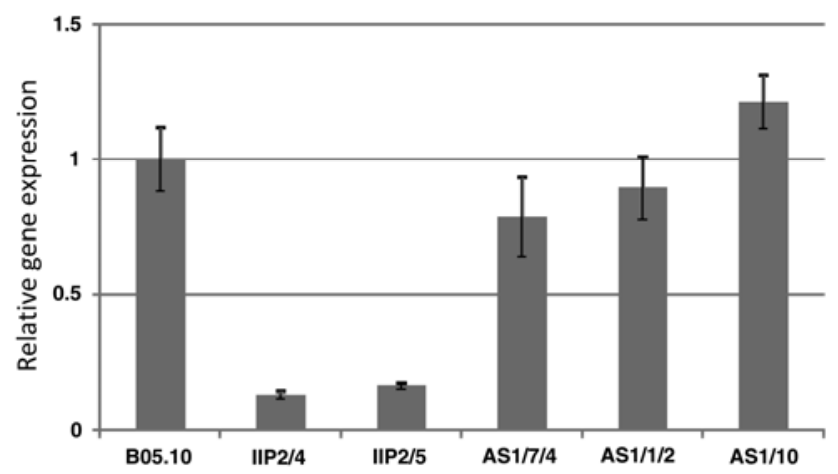

Fig. 4. Relative expression levels of $b c p p 2 A c$ in the wild-type B05.10, the hairpin mutants HP2/4 and HP2/5, and the antisense mutants AS 1/7/4, AS $1 / 1 / 2$, and AS1/10. Strains were grown for 3 days on complete medium. RNA was isolated and used for quantitative reverse-transcription polymerase chain reaction. Relative expression levels were normalized to the mean of the expression of three reference genes (tubulin, elongation factor, and actin). The expression of $b c p p 2 A c$ in the wild-type was set to 1 . Data shown are the average of two independent experiments; standard errors are indicated.

Table 1. Examples of identified open reading frames (ORF) possibly involved in pathogenicity

\begin{tabular}{|c|c|c|c|c|}
\hline Mutant & Phenotype & Tagged locus & $\begin{array}{c}\text { Site of } \\
\text { integration }\end{array}$ & Putative gene function (BlastX) \\
\hline PA58 & Type 2 & BC1G_14021 & ORF & $\begin{array}{l}\text { No similarity found; no conserved domains found; probably specific to } \\
\text { Botrytis cinerea and Sclerotinia sclerotiorum }\end{array}$ \\
\hline PA139 & Type 2 & BC1G_15863 & Upstream & spt 3 , Ajellomyces capsulatus, $E=8 \mathrm{e}-63$ \\
\hline PA436 & Type 2 & BC1G_01081 & Upstream & Hypothetical protein FG03950.1 Gibberella zeae, $E=6 \mathrm{e}-55$ \\
\hline PA556 & Type 2 & BC1G_15813 & Downstream & Heterokaryon incompatibility protein, Neurospora crassa, $E=7 \mathrm{e}-37$ \\
\hline PA1407 & Type 2 & BC1G_10264 & Upstream & DnaJ domain protein Aspergillus fumigatus A1163, $E=1 \mathrm{e}-19$ \\
\hline PA2512 & Type 3 & BC1G_15863 & Upstream & spt 3 , Ajellomyces capsulatus, $E=8 \mathrm{e}-63$ \\
\hline PA2810 & Type 1 & BC1G_02686 & ORF & Related to regulator of deoxyribodipyrimidine photo-lyase PHR $1, N$. crassa, $E=0.0$ \\
\hline PA3009 & Type 1 & BC1G_08695 & Downstream & Exocyst complex component EXO84, $N$. crassa, $E=0.0$ \\
\hline PA3009 & Type 1 & BC1G_08696 & Upstream & Serine/threonine protein phosphatase PP2A-2 catalytic subunit, $N$. crass $a, E=0.0$ \\
\hline PA3070 & Type 1 & BC1G_11672 & Upstream & Putative microsomal signal peptidase subunit SPC12, Aspergillus clavatus, $E=3 \mathrm{e}-22$ \\
\hline PA3135 & Type 1 & BC1G_10712 & Upstream & Cytokinesis protein sepA $N$. crassa, $E=0.0$ \\
\hline
\end{tabular}


bclg_08695. Therefore, functional characterization was focused on bc1g_08696 in the following studies.

RT-PCR was done initially in the wild type to determine whether the ORF bclg_08696 was, indeed, transcribed and that the automatic annotation was correct for both B05.10 and T4 (data not shown); bclg_08696 consists of 1,326 nucleotides comprising six introns and probably codes for the catalytic subunit of a type PP2A phosphoprotein phosphatase (PP2A), which is a heterotrimeric protein composed of one catalytic and two regulatory subunits (EC 3.1.3.16).
PP2As play an important role in many organisms in several cellular processes, including signal transduction, cell growth and morphology, differentiation, and metabolism. In $N$. crassa, the highly related PP2A is among other functions involved in regulation of the circadian clock. The gene that codes for the catalytic subunit $p p h 1$ turned out to be essential for cell survival of N. crassa (Yang et al. 2004; Yatzkan and Yarden 1995). Also, in the closely related $S$. sclerotiorum, the gene coding for the PP2A catalytic subunit pphl is crucial for fungal growth and the regulatory subunit $\mathrm{rgbl}$ is involved in virulence (Erental et al. 2007).

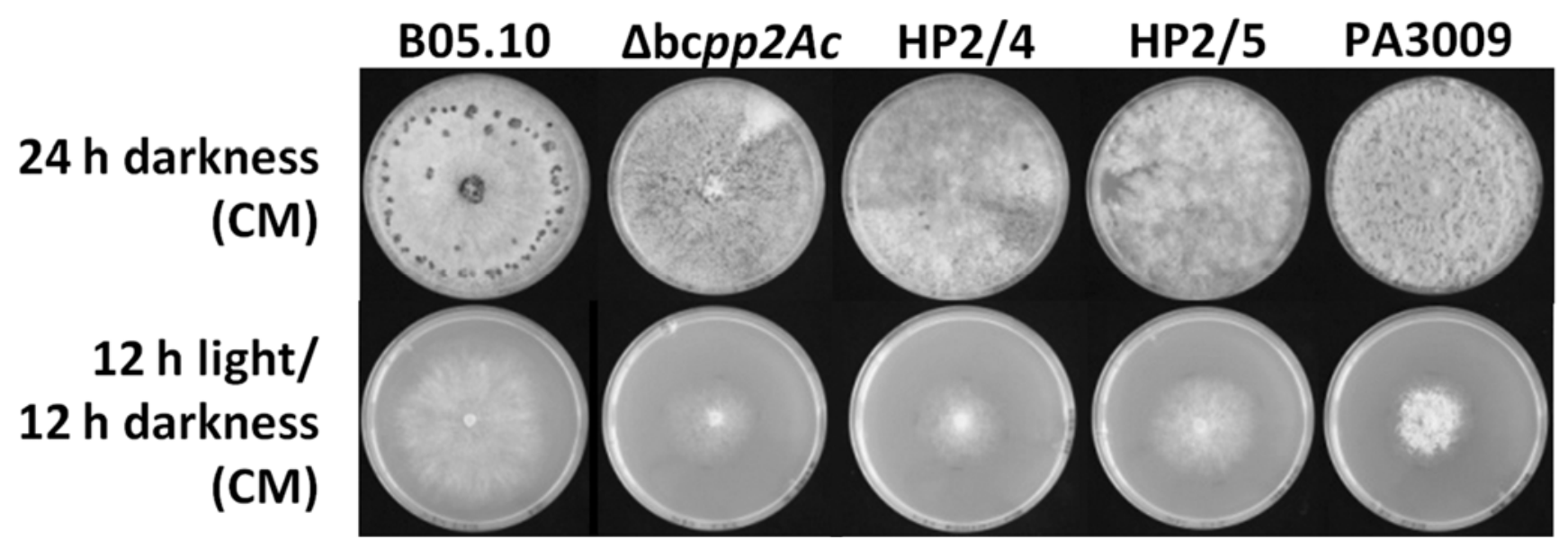

Fig. 5. Growth of Botrytis cinerea wild-type B05.10, Agrobacterium tumefaciens-mediated transformation (ATMT) mutant PA3009, heterokaryotic deletion mutant $\triangle p p 2 A c$, and silenced $b c p p 2 A c$ mutants HP2/4 and HP2/5 grown on complete medium (CM) for 3 days with alternating light and darkness and on CM grown in constant darkness for 20 days (CM darkness).

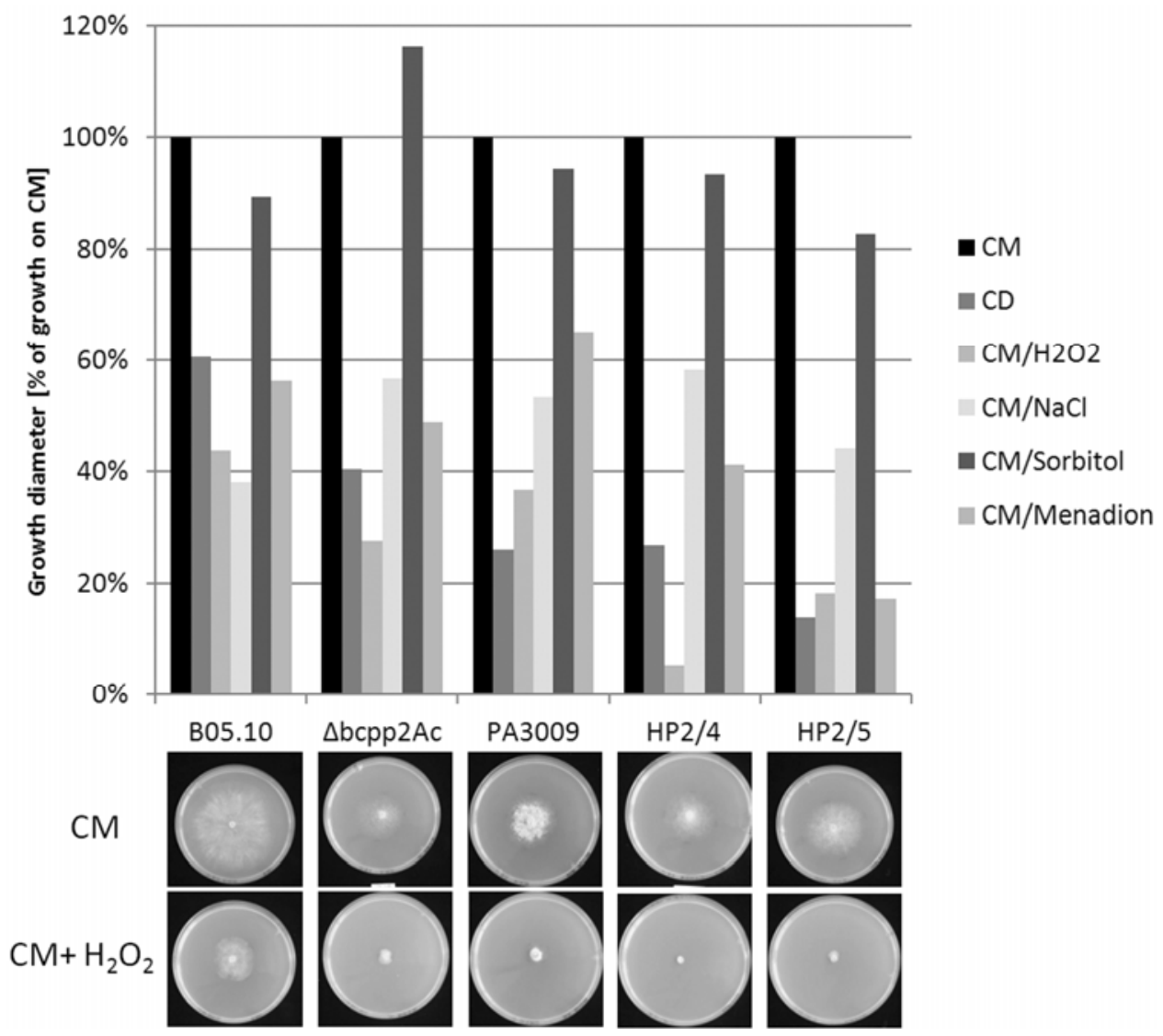

Fig. 6. Growth assay of the wild-type B05.10 and different $b c p p 2 A c$ mutant strains grown for 3 days on various media, including complete medium (CM) with different components causing oxidative as well as osmotic stress and minimal medium (CD). The growth on CM was considered to be 100\%. Oxidative stress was induced by the addition of $10 \mathrm{mM} \mathrm{H}_{2} \mathrm{O}_{2}$ or $250 \mu \mathrm{M}$ menadione; osmotic stress was induced by the addition of $0.8 \mathrm{M} \mathrm{NaCl}$ or $1 \mathrm{M}$ sorbitol. Mean values were calculated from five colonies with two measurements per colony. 
Replacement and silencing of gene locus bc1g_08696 (bcpp2Ac).

The PP2A-encdoding gene in S. sclerotiorum was shown to be essential, and also the insertional mutant strain PA3009 turned out to be heterokaryotic and could not be purified by several rounds of conidial subcultures (data not shown). Nevertheless, we initiated a replacement approach to delete ORF bclg_08696 to determine the link between the T-DNA integration and the phenotype of PA3009. A fragment containing the nourseothricin resistance cassette as well as the borders flanking the gene $5^{\prime}$ and $3^{\prime}$ was excised from deletion vector $\mathrm{p} \Delta b c p p 2 A c$ (Fig. 3A) and used to transform protoplasts of the wild-type strain B05.10. A number of nourseothricin-resistant transformants were analyzed by diagnostic PCR and Southern analysis to check for homologous integration events. Homologous integration at the $b c p p 2 A c$ locus could be detected in one case. However, the respective transformant $\triangle b c p p 2 A c_{-} 1$ still contained the $b c p p 2 A c$ wild-type fragment, indicating a heterokaryotic status of the primary transformant. After several rounds of single-spore isolation and attempts to purify the heterokaryon via protoplast isolation, the isolates still remained heterokaryotic (Supplementary Fig. S2), suggesting an essential role for bcpp2Ac. Preliminary characterization of the obtained mutant revealed that, although still being heterokaryotic, $\triangle b c p p 2 A c$ had a phenotype similar to that of the original insertion mutant PA3009 (which is also heterokaryotic; discussed above) in axenic culture and in planta regarding its morphology and growth of the mutant colonies; however, the phenotype seemed to be more severe. To verify these observations, we used an RNAi approach as described by Schumacher and associates (2008b). For this, two different constructs were cloned. One contained the bcpp $2 A c$ coding region in reverse orientation, leading to an antisense mRNA product (pAS_bcpp2Ac). The second vector contained an inverted repeat with a loop region, resulting in a hairpin structure in the relevant mRNA (pHP_bcpp2Ac) (Supplementary Fig. S3; details are provided below).
These two vectors were used to transform wild-type strain B05.10 and a set of transformants was generated. All transformants were tested by PCR and Southern analysis with respect to homologous integration at the bcniaD locus (discussed below) and number of integrations into the genome, respectively (data not shown). To validate the expected reduced level of bcpp $2 A c$ expression, quantitative real-time RT-PCR was applied. Three genes encoding actin, tubulin, and an elongation factor were used as reference genes. The $b c p p 2 A c$ expression level in the hairpin mutants HP 2/4 and HP 2/5 was reduced to 12 and $15 \%$, respectively, when compared with the wild type (Fig. 4). In contrast, in the AS mutants, the transcription level was not significantly altered compared with the wild type. Therefore, the mutants HP2/4 and HP2/5 were chosen for further analyses and compared with the heterokaryotic deletion mutant $\triangle b c p p 2 A c$, the wild-type B05.10, and the original ATMT transformant PA3009 with respect to virulence, growth, and differentiation.

As already observed for PA3009 and the heterokaryotic strain $\triangle b c p p 2 A c$, the silenced mutants had a retarded growth rate on $\mathrm{CM}$ and were severely affected when growing on CD. Regarding the production of sclerotia, neither the heterokaryotic strain $\Delta b c p p 2 A c$ nor strains HP2/4 and HP2/5 produced any sclerotia when grown in constant darkness for 2 weeks in contrast to the wild-type strain (Fig. 5). This is consistent with the phenotype exhibited by PA3009. Interestingly, when grown on media containing different stress-inducing components, the heterokaryotic deletion strain and the silenced strains were severely affected in their growth rates, indicating a high sensitivity to oxidative stress mediated by $\mathrm{H}_{2} \mathrm{O}_{2}$ and menadione. A strong reduction of growth rate was also seen on $\mathrm{CD}$, whereas osmotic stress mediated by sorbitol or $\mathrm{NaCl}$ did not affect the growth of the mutants (Fig. 6).

To test the impact of $b c p p 2 A c$ silencing and deletion on virulence, the different mutants were tested on bean leaves. The heterokaryotic deletion strain $\triangle b c p p 2 A c$ as well as strains HP2/4 and HP2/5 were strongly impaired in virulence (Fig. 7).

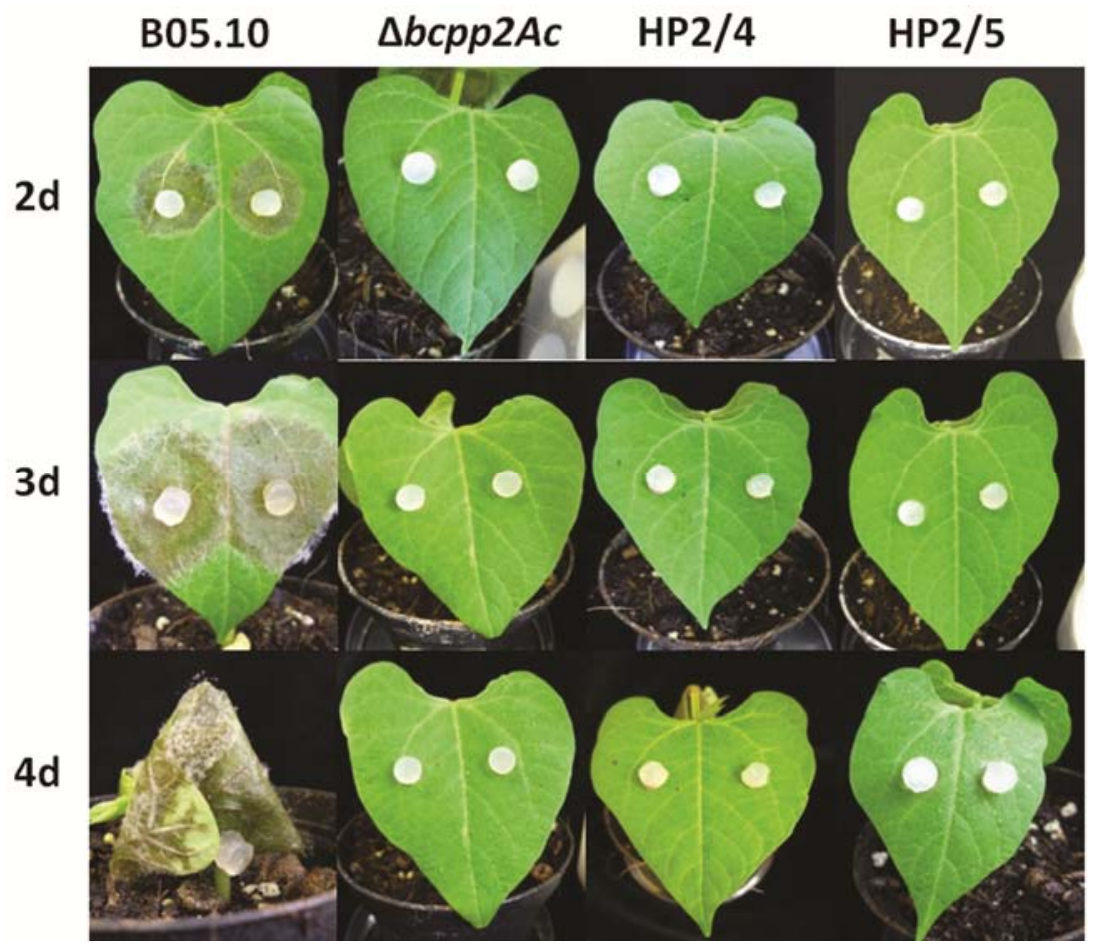

Fig. 7. Virulence tests on bean leaves of strains B05.10, the heterokaryotic deletion mutant $\Delta p p 2 A c$, and silenced $p p 2 A c-$ mutants HP2/4 and HP2/5. Bean leaves were inoculated with agar plugs colonized by nonsporulating mycelium and pictures were taken 2, 3, and 4 days postinfection (d). 
To summarize, the heterokaryotic deletion mutant $\triangle b c p p 2 A c$ and the hairpin mutants HP2/4 and HP2/5 exhibited phenotypes regarding virulence, differentiation, and growth rate similar to that of the original ATMT mutant PA3009, leading to the conclusion that the T-DNA integration in the promoter region of bcppA2c was responsible for the phenotype of PA3009. BcPP2Ac obviously is involved in virulence, vegetative growth, production of sclerotia, and resistance to $\mathrm{H}_{2} \mathrm{O}_{2}$ in B. cinerea.

\section{PA139.}

Another transformant which was characterized in more detail was the strain PA139. It was classified for virulence as belonging into category type 2 (i.e., it caused only primary lesions on bean plants and did not spread any further into the plant tissue). Interestingly, the analysis of the T-DNA integration sites revealed that the locus $b c 1 g \_15863$ identified to be the integration site for the mutant PA139 was also hit in the mutant PA2512, which was classified as belonging into virulence type 3 , meaning that it developed so-called secondary lesions. TAIL-PCR data for strain PA2512 were available only for the LB of the T-DNA integration, because the rescue of the RB sequence TAIL-PCR failed. In the transformant PA139, the isolation of both flanking sequences was successful and it turned out that the integration of the T-DNA caused a deletion of 288 nucleotides (Fig. 3B). To analyze the locus $b c l g \_15863$ in which the integration took place, and to verify the annotated intron and exon structures, RT-PCR was applied and revealed a possible incorrect annotation of the locus. RT-PCR data revealed that the renamed bcspt 3 codes for an ORF with 1,369 bp (translated sequence: $311 \mathrm{aa}$ ) and three introns instead of the annotated 833 bp. According to the revised annotation, the T-DNA integration led to a deletion of parts of the promoter and the $5^{\prime}$ region of the gene (more details are provided below).

The sequence shows high identity to the subunit spt3 of a SAGA-like transcriptional regulator complex (e.g., to spt3 of Ajellomyces capsalatus; $E=5 \mathrm{e}-114)$. Spt3 is important for virulence of $C$. albicans in mice and plays opposite roles in filamentous growth in Saccharomyces cerevisiae and C. albicans: deletion of spt 3 in $S$. cerevisiae impaired its filamentous growth, whereas spt3 deletion in $C$. albicans led to hyperfilamentous growth (Laprade et al. 2002). In Fusarium oxysporum, a gene homologous to spt 3 was also found through an ATMT screening and was thought to be involved in the virulence of the fungus (Michielse et al. 2009). Therefore, an attempt was made to delete the gene in $B$. cinerea.

\section{Replacement of gene locus bc1g_15863 (bcspt3).}

A gene replacement vector for locus $b c s p t 3$ was constructed and used to transform the wild-type strain B05.10 (Fig. 3B) (discussed below). After one round of single-spore isolation, homologous integration events were identified by PCR in independently generated mutants and verified by Southern analysis. Three mutants were shown to have integrated one copy of the replacement fragment, two of which were chosen for further characterization. Like the original ATMT strain PA139, the mutants $\Delta b c s p t 3-1$ and $\Delta b c s p t 3-19$ showed reduced growth rates on all tested media and a yellowish/brownish pigmentation that was distinct from the wild type. In contrast to PA139, the spt 3 deletion strains lost the ability to form conidia and to produce sclerotia when grown in constant darkness. Remarkably, the $\Delta b c s p t 3$ mutants exhibited an increased growth rate on different media relative to light-grown cultures when they were grown without light (Fig. 8A). To test the influence of stress conditions, the mutants were grown on media containing different stress-inducing components. It became obvious that the deletion of bcspt3 led to a higher sensitivity toward condi- tions affecting the cell wall membrane integrity, such as Calcofluor white, sodium dodecyl sulfate (SDS), and fluconazole. Retarded growth rates were also observed on medium causing oxidative stress supplemented with $10 \mathrm{mM} \mathrm{H}_{2} \mathrm{O}_{2}$ (Table 2; Fig. 8B).

The following virulence test had to be performed using agar plugs for the inoculation of the bean leaves rather than conidia due to the bcspt3-mutants' loss of ability to produce conidia. Mutants $\Delta b c s p t 3-1$ and $\Delta b c s p t 3-19$ developed no

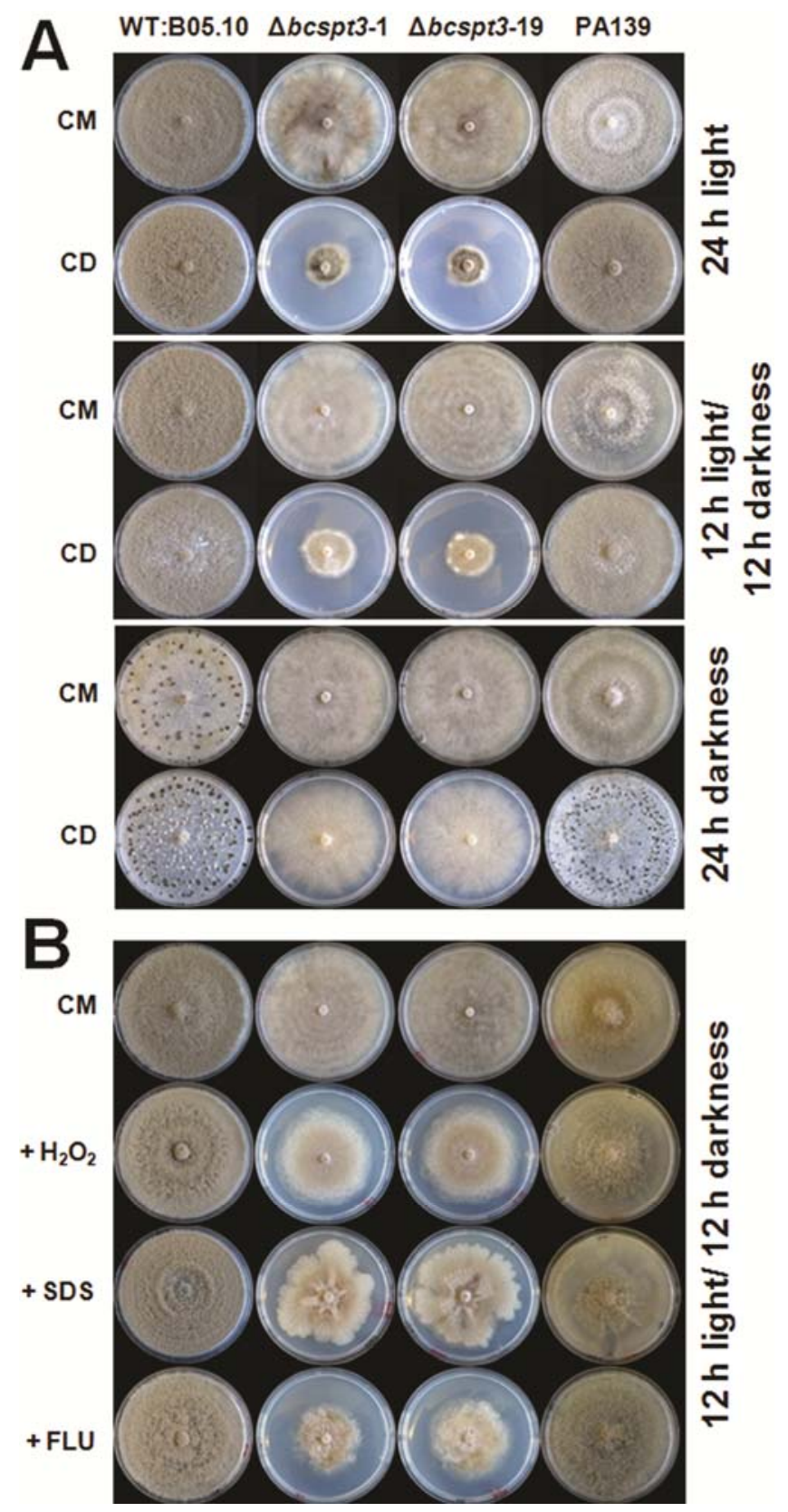

Fig. 8. Impact of BcSPT3 on growth, light-dependent differentiation, and stress response. A, Growth rates and differentiation is response to light. The Agrobacterium tumefaciens-mediated transformation (ATMT) strain PA139, bcspt3 deletion mutants, and the wild-type (WT) B05.10 were incubated for 14 days on complete medium (CM) and minimal medium (CD) under different light conditions. B, Effect of stress conditions on growth rates. The ATMT strain PA139, bcspt3 deletion mutants, and the WT B05.10 were incubated for 10 days on CM supplemented with $10 \mathrm{mM}$ $\mathrm{H}_{2} \mathrm{O}_{2}$ to induce oxidative stress and with $0.025 \%$ sodium dodecyl sulfate or fluconazole at $5 \mu \mathrm{g} / \mathrm{ml}$ to induce membrane stress. Colony diameters were measured and evaluated after 3 days of incubation with alternating light and darkness. 
visible symptoms on intact bean leaves (Fig. 3B, $\Delta b$ cspt $3-1=$ $\Delta b c 1 g \_15863$ ) or on prewounded leaves (data not shown) and, therefore, can be regarded as nonpathogenic. The differences observed between the $\Delta b c s p t 3$ mutants and the original strain PA139 can be explained by the integration modus of the T-DNA into strain PA139: apparently, only the promoter region and, in addition, the $5^{\prime}$ region of the gene has been deleted by T-DNA integration. This would imply that differences between the bcspt 3 knock-out mutant and PA139 could be due to a still-functional part of the gene in PA 139.

\section{PA436 and PA58.}

The next mutant that was analyzed with respect to the linkage of T-DNA insertion and observed phenotype was mutant PA436, which belongs in virulence category type 2 . Integration of the T-DNA led to a deletion of $41 \mathrm{bp}$ at the insertion point and was found 138 bp upstream of ORF bclg_01081. Bclg_ 01081 codes for a bZIP transcription factor (more details are provided below). A gene replacement approach resulted in two independently isolated mutants that are phenotypically identical to the wild type concerning growth on different media, differentiation, and virulence: when tested on bean leaves, the bclg_01081 deletion mutants showed disease symptoms indistinguishable from the wild type (Fig. 3C). In this case, the integration of the T-DNA was not linked to the original ATMT mutant's phenotype.

The fourth mutant to be characterized was mutant PA58, which was also classified as type 2 regarding its virulence. The T-DNA integration was found to be in the intron of ORF bclg_14021 and resulted in a deletion of $27 \mathrm{bp}$ at the insertion point. RT-PCR experiments confirmed the computational annotation of the ORF and the transcription of the gene under the tested conditions (data not shown). Bclg_14021 encodes a protein of 84 aa that does not contain any known domains.

It seems to be unique to $B$. cinerea and its close relative, S. sclerotiorum (supercontig 20 775898-775966; 776243776342), because it does not show any similarity to other published sequences in the databases using BLAST algorithms. Gene replacement of $b c 1 g_{-} 14021$ (Fig. 3D) achieved two independently created deletion mutants that were analyzed as described. The deletion of $b c 1 g \_14021$ did not lead to a reduction in virulence on bean plants (Fig. 3D); the mutants developed disease symptoms like the wild type, suggesting that, in this case also, the T-DNA integration was not linked to the phenotype of the ATMT mutant.

Summarizing the results obtained, a significant role in virulence of $B$. cinerea could be confirmed for two of the four genes which have been analyzed in detail. This role has been demonstrated by the phenotype of the original ATMT mutant, and by the targeted inactivation or silencing of the hit locus.

\section{DISCUSSION}

The generation of random mutant collections via ATMT has been widely used in different fungal species to identify virulence factors (Betts et al. 2007; Gupta and Chattoo 2008; Idnurm et al. 2009; Michielse et al. 2009; Walton et al. 2005). Here, we describe the initial analysis of a newly created library of 2,367 mutants in $B$. cinerea that is currently being extended and for which analysis is still continuing.

In this study, the prerequisites for the use of an ATMT-based mutant collection to identify new factors involved in virulence in $B$. cinerea were examined and-confirming and extending the pioneering studies of Rolland and associates (2003) - it could be validated that ATMT, indeed, appeared to be a suitable transformation method with a high transformation rate. In addition, in approximately $5 \%$ of the cases, we were able to obtain stable mutants that showed a significant reduction in virulence, a notable result because most of the mutants still display a heterogenic status even after performing single-spore isolation. In this work, the latter phenomenon proved to be a crucial benefit for the identification of factors that are decisive for cell viability and for which a targeted knock-out approach would otherwise be lethal. In addition, the commonly observed integration into the promoter region of an ORF contributed to the identification of factors that are indispensable for cell survival. On the other hand, it is still surprising that most of the obtained mutants are not homokaryotic with regard to the T-DNA integration locus, meaning that most of them still contain a functional allele of the hit integration site and yet display a strong phenotype.

Rolland and associates (2003) could show that B. cinerea could be efficiently transformed using Agrobacterium tumefaciens, creating mutants that had integrated the T-DNA randomly at single sites (as shown by Southern analysis). Also, in our study, a high percentage of T-DNA integration events proved to be single ones, as described for yeasts, many filamentous fungi, and plants (Alonso et al. 2003; Betts et al. 2007; Blaise et al. 2007; Bundock et al. 2002; Michielse et al. 2005, 2009).

Blaise and associates (2007) emphasized the importance of the preservation of T-DNA borders during the process of integration for the rescue of the flanking sequences, which enabled them to rescue at least $45 \%$ of the analyzed transformants from one side of the T-DNA flanking regions. Rolland and associates (2003) only rescued the T-DNA adjacent to the LB of the integrated T-DNA in $B$. cinerea. In contrast, in the present study, we were able to obtain both T-DNA flanks adjacent to the integrations sites in $50 \%$ of the cases and, in $94 \%$ of the cases, at least one border sequence was rescued via TAIL-PCR and, in some cases, via inverse PCR. The facility to rescue the neighboring flanks of the integrated border sites and the presence of two independent genome sequences of two $B$. cinerea

Table 2. Effect of stress conditions on growth rates of wild-type (WT) B05.10 and $\Delta b c s p t 3$ mutants $^{\mathrm{a}}$

\begin{tabular}{llcccc}
\hline & & \multicolumn{3}{c}{ Diameters of colonies (mm) \pm standard deviations (control [\%]) } \\
\cline { 3 - 6 } Type of stress & \multicolumn{1}{c}{ Medium } & WT B05.10 & $\Delta$ bcspt3-1 & $\Delta$ bsspt3-19 & PA139 \\
\hline \multirow{2}{*}{ Oxidative } & CM, control & $72.2 \pm 4.3(100)$ & $35.6 \pm 4.7(100)$ & $35.7 \pm 3.0(100)$ & $35.0 \pm 2.7(100)$ \\
& $+10 \mathrm{mM} \mathrm{H} \mathrm{O}_{2}$ & $33.0 \pm 2.3(45.7)$ & $15.7 \pm 1.3(44.1)$ & $15.5 \pm 1.8(43.4)$ & $31.0 \pm 4.9(88.6)$ \\
Osmotic & $+500 \mu \mathrm{M} \mathrm{menadione}$ & $48.4 \pm 6.9(67.0)$ & $23.2 \pm 1.6(65.2)$ & $22.8 \pm 0.9(63.9)$ & $28.0 \pm 7.2(80.0)$ \\
& $+0.8 \mathrm{M} \mathrm{NaCl}$ & $40.5 \pm 1.0(56.1)$ & $26.2 \pm 1.1(73.6)$ & $27.6 \pm 1.6(77.3)$ & $17.0 \pm 2.9(48.6)$ \\
Cell wall & $+1.0 \mathrm{M} \mathrm{sorbit}$ & $69.5 \pm 2.3(96.3)$ & $35.5 \pm 2.8(99.7)$ & $34.7 \pm 2.5(97.2)$ & $32.7 \pm 2.4(93.4)$ \\
& CFW at $+2 \mathrm{mg} / \mathrm{ml}$ & $51.9 \pm 5.5(71.9)$ & $27.8 \pm 3.4(78.1)$ & $29.7 \pm 2.8(83.2)$ & $25.5 \pm 3.5(72.9)$ \\
Membranyyyy & CR at $+2 \mathrm{mg} / \mathrm{ml}$ & $60.5 \pm 1.8(83.8)$ & $27.9 \pm 3.2(78.4)$ & $29.6 \pm 1.9(82.9)$ & $24.6 \pm 1.9(70.3)$ \\
& SDS at +0.025 & $44.1 \pm 1.3(61.1)$ & $20.2 \pm 2.2(56.7)$ & $21.1 \pm 2.4(59.1)$ & $20.1 \pm 3.3(57.4)$ \\
& Fluconazole at $+5 \mu \mathrm{gg} / \mathrm{ml}$ & $43.8 \pm 1.9(60.7)$ & $11.9 \pm 0.6(33.4)$ & $11.6 \pm 0.7(32.5)$ & $35.2 \pm 5.4(100.6)$ \\
\hline
\end{tabular}

${ }^{\text {a }}$ Strains were grown for 3 days on complete medium (CM) containing the stressors as indicated. Mean values were calculated from five colonies with two measurements per colony . CFW $=$ Calcofluor white, $\mathrm{CR}=$ Congo red, and SDS = sodium dodecyl sulfate . 
strains (T4 and B05.10) enabled us to analyze the integration sites of the T-DNA in many cases and to make a declaration about the precise integration modus regarding the position of the T-DNA, deletion of DNA, and so on. The observations that we made concerning the truncation of the T-DNA borders, the integration of T-DNA and vector-DNA, and deletion and rearrangement of DNA are consistent with observations made in other fungi in terms of appearance and frequency of the events (Michielse et al. 2009). However, the integration mode of the T-DNA in B. cinerea seemed to be different from many other fungi and plants characterized thus far in regard to the frequency of which truncations occur on a particular border side. In B. cinerea, in $29 \%$ of all analyzed transformants, the attempt to amplify the sequences adjacent to the RB and, in $6 \%$ of both sides via TAIL-PCR, failed. This is probably due to a truncation of the RB which thereby leads to a deletion of primer binding sites and, consequently, to a failure of the TAIL-PCR. In one case, PCR analysis of a transformant revealed a deletion of even $600 \mathrm{bp}$ of the vector DNA adjacent to the RB (data not shown); such occurrences should be taken into general consideration when analyzing and evaluating T-DNA integration events in ATMT mutants in which the sequence data are obtained via TAIL-PCR.

For the establishment of an ATMT-based mutant library with the objective of identifying new genes involved in virulence, the random distribution of T-DNA throughout the whole genome is a desirable prerequisite. Studies in M. oryzae, however, revealed that, though the T-DNA integrations were found throughout the entire genome, there were preferences detected concerning the integration of T-DNA into promoter regions that were twice as high as expected (Betts et al. 2007; Meng et al. 2007). A bias of T-DNA integration toward integration into the promoter region of a gene was also found in other organisms such as Colletotrichum graminicola (Münch et al. 2011), C. neoformans (Walton et al. 2005), M. oryzae (Choi et al. 2007), or Arabidopsis thaliana (Alonso et al. 2003). Alonso and associates (2003) suggested that the bias toward promoters and $3^{\prime}$ untranslated regions (UTR) in A. thaliana may be due to the preferential interaction of the Vir proteins with the host proteins that are involved in the process of transcription. The relatively small number of analyzed transformants in this study can only give an indication of the extent of randomness: in $47 \%$ of all characterized $B$. cinerea mutants, the T-DNA insertions were found in promoters or $3^{\prime}$ UTR whereas, in $27 \%$ of the mutants, the integration was found in an annotated ORF. However, it should be noted that, to date, the total number of genes in B. cinerea can only be estimated (approximately 16,000 gene models) (B. cinerea genome project) and the "density" of coding regions still needs to be assessed. Therefore, a statistically validated statement about T-DNA distribution in relation to coding and noncoding regions is not reliable at this stage. In addition, it must be considered that, in our study, only the integrations that potentially led to a defined phenotype were analyzed. Therefore, these are not representative for all T-DNA integrations that took place in total, regardless of an observed phenotype. Keeping this in mind, it was nevertheless unexpected that T-DNA integrations like those in the bcspt 3 gene locus of $B$. cinerea occurred twice at the same site independently of each other and also, in two other mutants (PA556 and PA2421), the same genomic region (approximately 700 bp downstream of BofuT4_P085890) was shown to contain a T-DNA integration. These results indicate that certain features of the genome seem to facilitate the integration of the T-DNA, in the manner observed in the promoter of the lacl gene in Cryptococcus neoformans (Idnurm et al. 2009; Walton et al. 2005).

The obvious preference of integration into promoter regions in M. oryzae was discussed by Meng and associates (2007), who mentioned that this preference may hinder the establishment of a representative mutant library that ideally should represent tagged genes of the whole genome. However, the fact that they and others, such as Idnurm and associates (2004), emphasize the alteration of gene function via T-DNA integration preferentially into regulator regions provides an even deeper insight and allows a more differentiated analysis of phenotypes than the targeted deletions of the relevant genes. This is strongly underlined by our discovery of the bcpp $2 A c$ gene, the deletion of which is lethal and that could be identified only by partial loss of function or misregulation, hence supporting the potential of this method to identify essential genes.

The identification of genes involved in the development of a certain phenotype by ATMT obviously constitutes a powerful method. Nevertheless, it is apparently necessary to study each identified gene in more detail because it cannot be taken for granted that the T-DNA integration is, indeed, linked to the observed phenotype. As discussed by Michielse and associates (2009), there are many examples in other organisms that ATMT can cause mutations that are not linked to the actual T-DNA integration. Blaise and associates (2007) described a rate of $50 \%$ linkage between tag and phenotype of T-DNA mutants in L. maculans; in F. oxysporum, this linkage could be confirmed in five of seven tested mutants (Michielse et al. 2009) and, in M. oryzae, in 14 of 15 tested mutants (Jeon et al. 2007). Obviously, the ATMT itself can create mutations other than the ones that are due to the T-DNA integration; and, in addition, naturally occurring mutations still can occur in all strains analyzed. In our study, in two of four analyzed loci, the link between T-DNA integration and phenotype could be confirmed, and it could be proven by targeted gene replacement (or RNAi) that the relevant factors are, indeed, involved in virulence of $B$. cinerea. In contrast, for two additional mutants, the knock-out of the tagged loci did not alter the virulence of the mutants (i.e., the phenotype is not linked to the T-DNA integration), which would account for a rate which is in accordance with the findings in other systems described above.

\section{BcPP2Ac.}

One of the newly identified virulence factors is the catalytic subunit of a type PP2A phosphoprotein phosphatase. To prove the link between the T-DNA insertion and the phenotype of mutant PA3009, an attempt was made to delete bcpp2Ac. This was not successful because we were unable to purify the heterokaryotic mutant strains and concluded that deletion of the catalytic subunit of BcPP2A would be lethal and, as in most of the other studied fungi, BcPP2Ac is essential for cell viability. The link between the T-DNA insertion and the ATMT mutant's phenotype was finally proved by analyzing the heterokaryotic strain and by reducing the transcript level of BcPP2Ac via an RNAi approach. Both approaches led to comparable results and to a phenotype that resembles that of the original ATMT mutant, PA3009.

In $N$. crassa, PP2A plays a role in the regulation of the circadian clock (Yang et al. 2004) and, in F. verticilloides, deletion of cppl led to a $40 \%$ reduction in growth rate, an upregulation of fuminosin production, and an abnormal hyphal morphology (Choi and Shim 2008). Erental and associates (2007) could show in Sclerotinia sclerotiorum that PP2Ac is crucial for fungal growth and that it is involved in virulence. Inhibition of the PP2Ac-encoding gene pphl resulted in aberrant hyphal morphology and cessation of growth. In addition, the inhibition of the regulatory subunit $r g b l$ led to the inhibition of sclerotial maturation and reduced virulence. The same observations were also made in $B$. cinerea: the heterokaryotic bcpp $2 A c$ deletion strain as well as the bcpp $2 A c$ silenced strains exhibited an ab- 
normal morphology and were impaired in virulence and disturbed in their ability to produce sclerotia, indicating the same function for PP2Ac in B. cinerea.

The observations made concerning the phenotypes of $\triangle \mathrm{PP} 2 \mathrm{~A}$ mutants in different fungi underline the function of PP2A in the phosphorylative regulation in different morphological processes. They probably operate in concert with mitogen-activated protein kinases (MAPKs) and protein kinase A (PKA), as discussed by Erental and associates (2008). Egan and associates (2009) hypothesized that PP2A may act as a repressor in the regulation of PKA or its substrates, reducing its activity in Ustilago maydis. They further suggest that calcineurin (a type PP2B Ser/Thr protein phosphatase) functions as an antagonist to PKA protein phosphorylation. In other fungi, calcineurin also plays similar important roles to PP2A. In S. sclerotiorum, calcineurin is involved in sclerotial development, virulence, and cell wall biosynthesis (Harel et al. 2006). In B. cinerea, calcineurin and its downstream target BcCRZ1 (calcineurin-responsive zinc finger transcription factor) have been examined by Viaud and associates (2003) and Schumacher and associates (2008a). By performing cyclosporin A-mediated inhibition of calcineurin, Viaud and associates (2003) showed that calcineurin is necessary for hyphal morphology, formation of infection structures, and the expression of genes involved in secondary metabolism. These findings indicate that the importance of both phosphatases, PP2A and calcineurin, is comparable in fungi.

The transcription factor BcCRZ1 acting downstream of calcineurin has been extensively studied in $B$. cinerea. The $\Delta b c c r z 1$ mutants (Schumacher et al. 2008a) exhibited a phenotype similar to that of the $\Delta b c p p 2 A c$ mutants, suggesting the involvement in similar pathways. Both the $\Delta b c c r z l$ as well as the $\Delta b c p p 2 A c$ mutant were impaired in their virulence on bean leaves. Both mutations led to a reduction of growth rate on $\mathrm{CM}$ and to a cessation of growth on CD. Neither of the mutant strains was able to form sclerotia in darkness. Interestingly, the $\Delta b c c r z 1$ mutants as well as the $\Delta b c p p 2 A$ mutants were sensitive to oxidative stress caused by $\mathrm{H}_{2} \mathrm{O}_{2}$, indicating a possible involvement in the cellular stress response system. Further studies would be necessary to establish whether both components act in cooperation, as suggested by Schumacher and associates (2008a), in concert with SKN7, which is a response regulator known to be involved in the oxidative stress response in several fungi (Ohmiya et al. 1999; Singh et al. 2004; Wormley et al. 2005) and which was shown to be involved in calcineurin- or Crz1-dependent signaling (Williams and Cyert 2001) in S. cerevisiae.

To highlight another aspect of the regulating complex in which BcPP2Ac probably participates, the findings of Erental and associates $(2007,2008)$ have to be mentioned. They demonstrated that the PP2A activity in S. sclerotiorum is dependent on the function of NADPH oxidase (Nox) and that the MAPK Smk1 participates in the regulation of PP2A activity. In $B$. cinerea, the Nox mutants $\triangle b c n o x B$ and $\Delta b c n o x R$, as well as the deletion mutant of the stress-activated MAPK $\Delta b c s a k l$, show several features similar to those of the $\Delta b c p p 2 A$ mutant regarding growth, differentiation, virulence, or oxidative stress response (Segmüller et al. 2007, 2008). It can be suggested, especially in the context of the $\triangle b c p p 2 A$ mutants' sensitivity toward $\mathrm{H}_{2} \mathrm{O}_{2}$-induced stress, that BcPP2A may act in concert with the NOX system as part of the reactive oxygen species signaling network in $B$. cinerea which, in addition to BcSAK1, also involves other studied components such as the redoxregulating system thioredoxin (BcTRX1) and thioredoxin reductase (BcTRR1), and the transcription factor BAP1 (Temme and Tudzynski 2009). However, the link between these components and BcPP2A remains to be elucidated.
Spt 3.

Spt3 is a subunit of the multi-subunit SAGA coactivator complex for RNA polymerase II transcription and is needed for the transcription of $3 \%$ of the genes in S. cerevisiae (Lee et al. 2000). Virulence in Candida albicans is dependent on Spt3, as shown by Laprade and associates (2002). The same was found in $F$. oxysporum by Michielse and associates (2009), who also identified an SPT3-encoding gene via ATMT which was necessary for full virulence.

In $B$. cinerea, the spt 3 locus was hit twice in two different ATMT mutants. Both mutants were impaired in virulence, although the degree of impact on virulence of the mutant PA139 was more severe. According to the revised annotation of locus bclg_15863, the T-DNA integration led to a deletion of parts of the promoter and the $5^{\prime}$ part of the coding region of spt 3 . In PA2512, the rescue of the RB sequence failed and, therefore, no information regarding the precise integration site is available. This fact might explain the differences between both ATMT mutants. In addition, the more pronounced phenotype of the spt3 knock-out mutant is due to the deletion of the whole gene because the $s p t 3$ gene may still be functional in the ATMT mutants, albeit to differing extents. Furthermore, the mutant PA139 is not homokaryotic with respect to ORF bclg_15863, meaning that it still possesses wild-type copies of the gene. Because Spt3 is probably also required in $B$. cinerea for the transcription of a whole set of genes, it cannot be designated as a true pathogenicity factor. As Michielse and associates (2009) had assumed for F. oxysporum, Spt3 in B. cinerea might control a number of genes required directly or indirectly for virulence.

In addition, the growth rate of the $\Delta s p t 3$ mutants is reduced in the presence of the fungicide fluconazole or components affecting the cell membrane such as Calcofluor white and SDS, and also on medium mediating oxidative stress. The impaired growth rates are in agreement with the role of the SAGA complex in S. cerevisiae which was examined by Huisinga and Pugh (2004), who proposed that SAGA is involved in the transcription of stress-induced genes. To our knowledge, little research has been done in the field of SAGA function in filamentous fungi; our preliminary results in this respect provide a small insight into this aspect of global gene regulation, especially with regard to virulence.

In this study, we were able to identify two new factors involved in the complex process of virulence by creating a new ATMT library of B. cinerea. Considering the number of pathogenicity-related mutants that were created, one cannot expect that all factors contributing to the virulence of $B$. cinerea were being tagged in the mutant library. In consideration of the fact that none of the hitherto-known virulence factors of $B$. cinerea were detected thus far in the mutant screen, the creation of additional mutants with the aim of a complete coverage of all potential virulence genes of $B$. cinerea is now a priority. As mentioned at the outset, in 2009, a list of 102 genes was published which have been previously analyzed by targeting inactivation (Tudzynski and Kokkelink 2009); of these, only a set of 31 genes was linked to virulence. The phenotype of the relevant deletion mutants ranges from "nonpathogenic" for six genes to only "slightly reduced virulence" for nine of the genes analyzed. Because most of the deletions of genes without a visible phenotype are not published, the list of futile knock-outs probably is much longer. Idnurm and Howlett (2001) estimated that there are 60 to 360 virulence genes in phytopathogenic fungi. Their identification by the "reverse genetic approach" seems to be tedious and time consuming. In addition, as Tudzynski and Kokkelink outlined in their review (2009), many of the so called "classical" candidate genes that were hypothesized to take part in the virulence of $B$. cinerea in 
the past have now been analyzed. Furthermore, genome analyses demonstrated that $30 \%$ of the ORF encode proteins of unknown function. Therefore, starting from a defined phenotype, ATMT appears to be a valuable contribution to the identification of new virulence-related genes and to gaining new insight into the complex virulence system of $B$. cinerea.

\section{MATERIALS AND METHODS}

Strains and culture conditions.

Strain B05.10 of B. cinerea Pers. (Botryotinia fuckeliana (de Bary) Whetzel) is a putative haploid strain obtained after benomyl treatment of an isolate from Vitis spp. (Quidde et al. 1998), and is used as host strain for gene replacement experiments. Wild-type and mutant strains were grown on several complex media: potato dextrose agar (PDA) (Sigma-Aldrich Chemie, Steinheim, Germany) was supplemented with $10 \%$ homogenized leaves of French bean (Phaseolus vulgaris), yielding PDAB medium. Synthetic CM was made according to Pontecorvo and associates (1953). As CD, modified CzapekDox $\left(2 \%\right.$ sucrose, $0.1 \% \mathrm{KH}_{2} \mathrm{PO}_{4}, 0.3 \% \mathrm{NaNO}_{3}, 0.05 \% \mathrm{KCl}$, $0.05 \% \mathrm{MgSO}_{4} \times 7 \mathrm{H}_{2} \mathrm{O}$, and $0.002 \% \mathrm{FeSO}_{4} \times 7 \mathrm{H}_{2} \mathrm{O}, \mathrm{pH} \mathrm{5.0)}$ was used. For conidiation, the strains were incubated for 1 week at $21^{\circ} \mathrm{C}$ under constant light conditions (full spectrum, including near-UV light); for sclerotial formation, 4 weeks at $21^{\circ} \mathrm{C}$ in darkness. For DNA and RNA minipreparations, mycelium was grown for 3 to 4 days at $20^{\circ} \mathrm{C}$ on $\mathrm{CM}$ agar with a cellulose acetate (Cellophane) overlay. Plate assays were performed using CM agar, supplemented with Congo red, Calcofluor white, menadione, fluconazole (Sigma-Aldrich, St. Louis), $\mathrm{H}_{2} \mathrm{O}_{2}$ (AppliChem GmbH, Darmstadt, Germany), and SDS and as indicated. Colony diameters were measured 2 and 3 days postinoculation and experiments were repeated three times using five plates per condition and strain. Protoplasts were generated using glucanex (Novozymes, Aarhus, Denmark), added to $15 \mu \mathrm{g}$ of the linearized vector, and transformed according to Schulze Gronover and associates (2001). Resistant colonies were transferred to agar plates containing GB5 agar, supplemented with hygromycin B (Invivogen, San Diego, CA, U.S.A.) at $70 \mu \mathrm{g} / \mathrm{ml}$ or nourseothricin (Werner-Bioagents, Jena, Germany) at $70 \mu \mathrm{g} / \mathrm{ml}$. Single conidial isolates were obtained by spreading conidial suspensions on GB5 plates containing hygromycin B at $70 \mu \mathrm{g} / \mathrm{ml}$. The conidia were germinated and single colonies transferred individually to new plates containing the selection marker.

A. tumefaciens AGL 1 (AGL0 recA::bla pTiBo542 $[\Delta] \mathrm{T}$ Mop+ CbR) (Lazo et al. 1991) carries the binary vector pAG1 which was transferred into strain AGL1 following the electroporation protocol as described by Mattanovich and associates (1989), with minor adjustments using the electroporator 2510 (Eppendorf, Hamburg, Germany). Strain AGL1 was cultivated on carbenicillin at $0.1 \mathrm{mg} / \mathrm{ml}$ and kanamycin at $0.1 \mathrm{mg} / \mathrm{ml}$ containing Luria-Bertani medium at $28^{\circ} \mathrm{C}$.

Escherichia coli TOP10F' (Invitrogen, Carlsbad, CA, U.S.A.) was used for subcloning.

\section{Standard molecular methods.}

Fungal genomic DNA was isolated as described by Cenis (1992) and plasmid DNA was isolated using a plasmid DNA preparation kit (Qiagen $\mathrm{GmbH}$, Hilden, Germany). Fungal genomic DNA was transferred to Amersham Hybond- $\mathrm{N}^{+}$filters (GE Healthcare Limited, Hertfordshire, U.K.) after digestion with restriction enzymes and size-separation on a $1 \%$ agarose gel according to Sambrook and associates (1989) and hybridized to radioactively labeled DNA probes in Denhardt's hybridization solution (Sambrook et al. 1989). Filters were washed for $10 \mathrm{~min}$ in $2 \times \mathrm{SSC}(1 \times \mathrm{SSC}$ is $0.15 \mathrm{M} \mathrm{NaCl}$ plus
$0.015 \mathrm{M}$ sodium citrate) and $0.1 \%$ SDS and for $10 \mathrm{~min}$ in $1 \times$ SSC and $0.1 \%$ SDS. Hybridization and washing of the filters were carried out at $65^{\circ} \mathrm{C}$.

Standard PCR reactions were performed as described by Sambrook and associates (1989), using BioTherm DNA polymerase (GeneCraft GmbH, Lüdinghausen, Germany). Amplification products were cloned with the pCR2.1-TOPO-cloning kit from Invitrogen. A list of primers used is to be found in Supplementary Table S1.

DNA sequencing was carried out with the Big Dye Terminator v3.1 sequencing kit (Applied Biosystems, Foster City, CA, U.S.A.). After the PCR reaction, the samples were purified by column chromatography and sequenced in an ABI Prism capillary sequencer (model 3730). For sequence analysis, the program DNA Star (Madison, WI, U.S.A.) was used.

\section{Real-time PCR.}

Strains were grown for 3 days on CM. RNA was isolated from mycelial samples using the RNAgents total RNA isolation system (Promega, Mannheim, Germany). The samples containing $1 \mu \mathrm{g}$ of total RNA were digested with 1 unit of DNase (Promega) for $30 \mathrm{~min}$, and the first-strand cDNA was synthesized using the Superscript II RetroTranscriptase (Invitrogen), according to the manufacturer's instructions. The presence of genomic DNA was tested carrying out a PCR to amplify the whole ORF of the actin gene with the primers ACDNAFW and ACDNARV. In no case was amplification of genomic DNA observed. Real-time PCR was carried out using this cDNA template in an iCycler iQ Real-Time PCR system (Bio-Rad, Munich) with the Bio-Rad iQ SYBR Green supermix and primers. The annealing temperature of all the reactions was $60^{\circ} \mathrm{C}$ and time extension was $20 \mathrm{~s}$. Three different genes were used as reference genes to normalize the RNA amount in each sample: actin A (primers ARTPCRFW and ARTPCRRV), elongation factor (EFRTPCRFW and EFRTPC RRV), and tubulin (TBRTPCRFW and TBRTPCRRV). For each reaction, a pair of primers was designed in such a way that one of them bound in an exon-exon split, to avoid genomic DNA amplification. Therefore, for each gene, the PCR efficiency was between 90 and $110 \%$.

The relative expression of PP2A gene was calculated following the $\Delta \Delta \mathrm{Ct}$ method from the mean of two different determinations of the threshold cycle. Each PCR reaction was followed by a melting curve, to assure that there was only a product amplified. In no case was a product other than the expected amplicon produced. Two different samples (biological repeats) were tested and each reaction was performed threefold.

\section{ATMT of Botrytis cinerea.}

The protocol for the A. tumefaciens transformation of Botrytis cinerea was modified and adjusted as follows after the protocol described by de Groot and associates (1998). The binary vector pAG1 was constructed by replacing the resistance cassette of the binary vector pKS2 (Covert et al. 2001) by the hygromycin B resistance cassette composed of the E. coli hygromycin phosphotransferase gene $h p h$ under control of the oliC promotor from Aspergillus nidulans and the tub-terminator from B. cinerea.

A single colony of Agrobacterium tumefaciens containing the vector pAG1 was grown in Luria-Bertani medium containing carbenicillin $(0.1 \mathrm{mg} / \mathrm{ml})$ and kanamycin $(0.1 \mathrm{mg} / \mathrm{ml})$ at $28^{\circ} \mathrm{C}(180 \mathrm{rpm})$ overnight. The culture $(2 \mathrm{ml})$ was harvested by centrifugation $(10 \mathrm{~min}$ at $6,000 \mathrm{rpm})$ and the pellet was washed with $1 \mathrm{ml}$ of IM solution (Bundock et al. 1995) (1.25 M K-phosphate buffer [pH 4.8] at $0.8 \mathrm{ml} / \mathrm{liter}, 1 \% \mathrm{CaCl}_{2}$ at $1 \mathrm{ml} /$ liter, trace element solution at $5 \mathrm{ml} / \mathrm{liter}, 0.1 \% \mathrm{FeSO}_{4}$ at $1 \mathrm{ml} /$ liter, $1 \mathrm{M}$ MES-Puffer $[\mathrm{pH} \mathrm{5.5}$ ] at $40 \mathrm{ml} / \mathrm{liter}, 50 \%$ 
glycerol [vol/vol] at $10 \mathrm{ml} / \mathrm{liter}, \mathrm{MgSO}_{4} \times 7 \mathrm{H}_{2} \mathrm{O}$ at $0.6 \mathrm{~g} / \mathrm{liter}$, $\mathrm{NH}_{4} \mathrm{NO}_{3}$ at $0.5 \mathrm{~g} /$ liter, and $\mathrm{NaCl}$ at $0.3 \mathrm{~g} /$ liter; trace element solution consisted of $\mathrm{ZnSO}_{4} \times 7 \mathrm{H}_{2} \mathrm{O}$ at $0.1 \mathrm{~g} / \mathrm{liter}, \mathrm{CuSO}_{4} \times 5$ $\mathrm{H}_{2} \mathrm{O}$ at $0.1 \mathrm{~g} /$ liter, $\mathrm{H}_{3} \mathrm{BO}_{3}$ at $0.1 \mathrm{~g} /$ liter, $\mathrm{MnSO}_{4} \times \mathrm{H}_{2} \mathrm{O}$ at 0.1 g/liter, and $\mathrm{NaMoO}_{4} \times 4 \mathrm{H}_{2} \mathrm{O}$ at $0.1 \mathrm{~g} /$ liter), centrifuged again, and resuspended in $200 \mu \mathrm{l}$ of IM. Subsequently, the bacterial suspension was grown in $5 \mathrm{ml}$ of IM medium with or without acetosyringone $(200 \mu \mathrm{M})$ at $28^{\circ} \mathrm{C}(180 \mathrm{rpm})$ until an optical density $(578 \mathrm{~nm})$ of 0.7 was reached.

$B$. cinerea conidia were obtained by growing the strain for 8 days on PDAB medium. Conidia were harvested using $3 \mathrm{ml}$ of $\mathrm{PZ}$ solution $(\mathrm{NaCl}$ at $0.9 \mathrm{~g} / \mathrm{liter})$, filtrated, centrifuged for 10 min at 4,000 rpm, and resuspended in $1 \mathrm{ml}$ of PZ solution. The conidia suspension was subsequently adjusted to $10^{8}$ spores per milliliter. The conidia suspension $(100 \mu \mathrm{l})$ was then mixed with $100 \mu \mathrm{l}$ of the Agrobacterium suspension and plated on nitrocellulose filters placed on IM plates containing $0.1 \%$ glucose $(\mathrm{wt} / \mathrm{vol})$ with or without acetosyringone $(200 \mu \mathrm{M})$. The plates were incubated at $28^{\circ} \mathrm{C}$ for 2 days. The filters were then transferred to GB5 medium containing hygromycin B at 70 $\mu \mathrm{g} / \mathrm{ml}$ and $200 \mathrm{mM}$ cefotaxime and incubated for 7 to 14 days at $22^{\circ} \mathrm{C}$ in darkness. Resistant colonies were subsequently transferred to GB5 medium containing hygromycin B at 70 $\mu \mathrm{g} / \mathrm{ml}$ and $200 \mathrm{mM}$ cefotaxime. After 1 week, the primary transformants were subjected to one round of single-spore isolation as described above.

\section{TAIL-PCR.}

To rescue the DNA-sequences adjacent to the T-DNA integration sites, TAIL-PCR was performed as described by Liu and Whittier (1995) and Terauchi and Kahl (2000), with minor adjustments. For the isolation of the LB and RB flanking sequences, five specific primers in nested positions were used in combination with one 10 -mer random primer. In total, 10 different 10-mer random primers (random amplified polymorphic DNA [RAPD]) were used. To perform the primary PCR, $50 \mathrm{ng}$ of genomic DNA was used. The amounts of primers used were $0.2 \mu \mathrm{M}$ specific and $2 \mu \mathrm{M}$ RAPD primer in the primary and secondary reaction, and $0.2 \mu \mathrm{M}$ specific and $0.2 \mu \mathrm{M}$ RAPD primer in the tertiary reaction. The tertiary TAIL-PCR products were cloned into the vector pCR2.1-TOPO (Invitrogen) and subsequently sequenced. The sequences were used to search for similarities against B05.10 database (Broad Institute), the T4 $B$. cinerea database at the French National Sequencing Center (Genoscope, France), and the National Center for Biotechnology Information using BLASTN and BLASTX algorithms.

\section{Inverse PCR.}

In cases in which TAIL-PCR failed, inverse PCR was used as described by Ochman and associates (1988), with minor modifications. As a template for the PCR, genomic DNA was restricted with $C l a \mathrm{I}$ or $B g l \mathrm{II}$ and primers PpAGout and TpAGout were used.

\section{Virulence assays.}

For the detached leaf assay, fully developed tomato leaves were cut, rinsed with water, and placed on moist filter paper in a Nunc plate. On each pinna, a droplet of PDA was placed and inoculated with a mycelia plug of a Botrytis strain. After 3 days at room temperature, growth beyond the agar drop in the leaf was evaluated semiquantitatively compared with the wild type. Mutants with significantly reduced in planta growth were subjected to the standard quantitative intact plant assay:

Primary leaves of $P$. vulgaris were inoculated with conidia from 10-day-old PDAB-agar cultures as described by Schulze Gronover and associates (2001). As indicated, in some experi- ments, agar plugs taken from 3-day-old GB5 agar cultures were used for inoculation. The infected plants were incubated in a plastic propagator box at $20^{\circ} \mathrm{C}$ under natural illumination. At least eight infections per strain were monitored and documented photographically. Disease symptoms were scored until 12 days after inoculation.

\section{Replacement of bc1g_08696 (bcpp2A).}

For construction of the replacement vector, primers Phosph LFa/Phosph_LFb and Phosph_RFa/Phosph_RFb were used to amplify the 5' and 3' flanking regions of bclg_08696. The PCR-products were cloned into vector pCR2.1-TOPO (Invitrogen) and subsequently excised with SacI/SacII and HindIII/ XhoI, respectively, for cloning into the vector pNR1 (Malonek et al. 2004) (Fig. 3). The replacement fragment was finally excised with SacI and XhoI for transformation of strain B05.10. Homologous integration events in nourseothricin-resistant transformants were detected by diagnostic PCR using the primers tubT and pLOF-oliP binding in the nourseothricin resistance cassette and the primers Phosph_HI_LF-F and Phosph_HI RF-R, binding upstream and downstream of the bcpp $2 A$ flanking regions. The presence of the wild-type copy of the gene was shown using primer combination Phosph_WT_R and Phosph_HI_LF-F. To perform Southern blot analysis, genomic DNA of the transformants was restricted with PstI and hybridized with the $5^{\prime}$ flank of bcpp $2 A$. Due to an additional PstI-site in the replacement vector, the homologous integration event achieved a hybridizing fragment of $2.3 \mathrm{~kb}$ whereas the wild-type situation produced a hybridizing fragment of $3.9 \mathrm{~kb}$.

\section{Silencing of bcpp2A.}

For the construction of silencing constructs, a vector containing the noncoding $5^{\prime}$ and $3^{\prime}$ flanks of the gene bcniaD encoding the nitrate reductase were used to mediate homologous integration of the silencing constructs at the bcniaD locus. This should guarantee the creation of mutants that exhibit an identical genetic background. The vector $\mathrm{p} \Delta b c n i a D+$

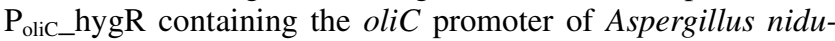
lans for ensuring high expression of the silencing constructs was used as described previously (Schumacher et al. 2008b). To generate the vector $\mathrm{p} \Delta b c n i a D+\mathrm{P}_{\text {olic }}$ natR containing the nourseothricin resistance gene, the cassette was amplified by PCR using the primers trpC-promF (BamHI) and trpC-promR (sites for NcoI, NotI, XbaI, ApaI, and SpeI), and pZPnat1 (GenBank, AY631958.1) as a template. The PCR product was cloned into pCR2.1-TOPO (Invitrogen), isolated with BamHI and NcoI, and finally ligated into the respective restriction sites of $\mathrm{p} \Delta b c n i a D+\mathrm{P}_{\text {olic }}$, creating $\mathrm{p} \Delta$ bcniaD $+\mathrm{P}_{\text {olic_natR. To }}$ silence ссрp $2 A$, two silencing approaches were followed: the expression of an antisense fragment and the expression of an inverted repeat of the target gene. The corresponding fragments were generated from the coding region of $b c p p 2 A$. The 497-bp antisense fragment was amplified by PCR using the primer PP2A-F1-SpeI and PP2A-R1-NcoI, cloned into pCR2.1TOPO, and reisolated with SpeI and NcoI. This fragment was then ligated with the SpeI/NcoI-digested $\mathrm{p} \Delta b c n i a D+\mathrm{P}_{\text {olic_natR, }}$ creating pbcpp $2 A-\mathrm{AS}$. The hairpin inverted repeat fragments (HP1 and HP2) were generated by PCR using the primers PP2A-F2-NcoI and PP2A-R2-SalI for the generation of 500bp sense fragment and the primers PP2A-F1-SpeI and PP2AR3-SalI for the 400-bp antisense fragment. After cloning of the PCR products into pCR2.1-TOPO, the sense fragment (HP1) was isolated with $\mathrm{NcoI}$ and SalI and the antisense fragment (HP2) with SalI and SpeI. The fragments were ligated into NcoI/SpeI-digested p $\Delta b c n i a D$-natR, creating pbcpp $2 A-H P$. Prior to transformation of B05.10, the plasmids were digested 
with SacII in order to linearize the vectors. The nourseothricinresistant transformants were analyzed by PCR for homologous integration of the silencing constructs at the bcniaD locus. For that, primers bcniaD-hi3R and pCSN44-trpC-P, which bind in the promoter of the nourseothricin resistance cassette, were combined.

\section{Identification and replacement of bc1g_15863 (bcspt3).}

Bclg_15863/bcspt3 was identified in two independent ATMT lines. Whereas both LB- and RB-flanking sequences were obtained for strain PA139, only the LB-flanking sequence could be amplified for PA2512. In PA139, the T-DNA integration occurred in B05.10 supercontig 1.203 (28,469 to 28,757) and resulted in a deletion of 288 bp (Fig. 3B). The predicted ORF bclg_15863 was found in the B05.10 database to be close to the T-DNA in PA139/PA2515 (437 to $150 \mathrm{bp}$ upstream). To revise the automatic annotation of $b c l g \_15683$, a cDNA fragment was generated and sequenced using primers Bclg 15863-RT-F1 and Bc1g_15863-RT-R1. The predicted gene structure was incorrect because the ORF comprises $1,369 \mathrm{bp}$ and three introns of 290,87 , and $53 \mathrm{bp}$, resulting in a protein of 311 aa instead of 210 aa. Hence, the T-DNA replaces a region comprising the start codon and the first $135 \mathrm{bp}$ of the revised ORF, which was named bcspt 3 due to its similarity with the SPT3 transcription factor of Saccharomyces cerevisiae. Knock-out constructs for bcspt 3 were produced using the homologous recombination system in yeast, as described previously (Colot et al. 2006). The $5^{\prime}$ and $3^{\prime}$ regions of bcspt 3 ( 1.095 and $0.371 \mathrm{~kb}$ ) were amplified from genomic DNA of $B$. cinerea wild-type strain B05.10 using the primer pair $\mathrm{Bclg}$ 15863-5F/Bclg_15863-5R and Bclg_15863-3F/Bclg_158633R, respectively (Fig. 3B).

These primers not only contained sequences to amplify the $5^{\prime}$ and $3^{\prime}$ regions of bcspt 3 but also contained sequences homologous to the resistance cassette and the yeast plasmid pRS426 (Christianson et al. 1992). By this, the PCR reaction not only amplified the gene flanks but also added specific overhangs to the $5^{\prime}$ and $3^{\prime}$ flanks homologous to the resistance cassette and the yeast plasmid pRS426, respectively. The hygromycin resistance cassette containing the $h p h$ gene of $E$. coli under control of the $\operatorname{trp} C$ promoter of $A$. nidulans was generated with primers pCSN44-hphF and pCSN44-hphR using pCSN44 as a template (Staben et al. 1989). The three PCR fragments together with the EcoRI/XhoI linearized vector pRS426 were co-transformed into the uracil-auxotrophic $S$. cerevisiae FY834 (Winston et al. 1995), where homologous recombination took place. Transformants were selected on SD plates lacking uracil. DNA from uracil-prototrophic yeast colonies was isolated with the GeneJET Plasmid Miniprep Kit (Fermentas, Vilnius, Lithuania), including an initial step of disrupting yeast cells by addition of glass beads. The DNA was then utilized as template to amplify the bcspt 3 replacement construct by use of primers Bclg_15863-5F and Bclg_15863$3 \mathrm{R}$. The $\Delta b \operatorname{cspt} 3$ fragment was subsequently transformed into $B$. cinerea $\mathrm{B} 05.10$, which was used as the general recipient strain. Homologous integration events in hygromycin-resistant transformants were detected by diagnostic PCR using the primers pCSN44-hph-trpC-T and pCSN44-trpC-P, binding in the hygromycin resistance cassette and the primers $\mathrm{Bclg}$ 15863-hi5F and Bclg_15863-hi3R, and binding upstream and downstream of the bcspt3-flanking regions. Single-spore isolates were screened for the absence of the bcspt 3 allele by using primers $B c 1 g \_15863-W T-F$ and $B c l g \_15863-W T-R$ matching the substituted coding region of bcspt3. Two independent transformation approaches resulted in 28 hygromycinresistant transformants. All transformants were submitted to diagnostic PCR and it was shown that 12 of them had under- gone the homologous recombination event leading to the replacement of bcspt3. The primary transformants $\mathrm{T} 5, \mathrm{~T} 18$, and T19 were subjected to single-spore isolation. Isolates were checked by PCR for the absence of the bcspt 3 ORF. Taken together, three independent deletion mutants of bcspt 3 have been generated. In order to show that the mutants did not contain additional copies of the replacement fragment, genomic Southern blot analyses have been performed. For this, the genomic DNA of strain B05.10 and $\Delta b c s p t 3$ mutants was digested with EcoRI and hybridized to the $3^{\prime}$ flank with bcspt3. The wildtype fragment with a size of $5.0 \mathrm{~kb}$ was replaced by a $1.3-\mathrm{kb}$ fragment in the $\Delta b c s p t 3$ mutants due to an additional EcoRI restriction site within the hygromycin resistance cassette (Fig. 3B; data not shown).

\section{Identification and replacement of bc1g_01081.}

Bclg_01081 encoding a bZIP transcription factor was found to be tagged in ATMT line PA436 (Fig. 3C). In this mutant, the T-DNA replaces a region of 42 bp upstream of the predicted ORF (B05.10 supercontig 1.3: 354,856 to354,899). Data derived from RT-PCR analyses revealed the possibility of a third intron. Due to its absence or presence, two different transcript sizes have been found, resulting in proteins of 595 and 570 aa, respectively. Thus, the ORF comprises 2,057 bp and two or three introns of 158,111 , and $79 \mathrm{bp}$. For replacement of bclg_01081, the 5' $(0.929-\mathrm{kb})$ and $3^{\prime}(1.114-\mathrm{kb})$ flanks were amplified by using the primer pairs Bclg_01081-5F/-5R and Bc1g_01081-3F/-3R (Fig. 3C), and were subsequently transformed together with the hygromycin resistance cassette into $S$. cerevisiae FY 834, as described previously. The replacement fragment was amplified by PCR and transformed into $B$. cinerea B05.10. Primer combinations Bclg_01081-hi5F/pCSN44hph-trpC-T and pCSN44-trpC-P/Bclg_01081-hi3R were used for PCR to detect the homologous integration of the replacement fragment in the nine obtained hygromycin-resistant transformants. The Bc1g_01081 allele was detected using the primers Bc1g_01081-WT-F and Bc1g_01081-WT-R. All transformants have undergone homologous integration and, for two primary transformants, homokaryotic mutant lines have been generated by isolation of single spores. For Southern blot analysis, genomic DNA of the strains (B05.10, T6, and T9) was digested with HindIII and hybridized to the $5^{\prime}$ flank. Due to the loss of a HindIII restriction site in the knock-out mutants, the wildtype fragment (approximately $5.0 \mathrm{~kb}$ ) was replaced by a bigger fragment (approximately $9.0 \mathrm{~kb}$ ) in the mutant strains (Fig. $3 \mathrm{C}$; data not shown).

\section{Identification and replacement of $b c 1 g \_14021$.}

The small putative ORF $b c l g \_14021$ was disrupted by the T-DNA in PA58. Computational predictions in both B05.10 and T4 databases yielded identical results. Accordingly, the ORF comprises only $428 \mathrm{bp}$ and is interrupted by one large (174 bp) intron (Fig. 3D). The deduced protein contains 84 aa and does not exhibit conserved protein domains or similarity to known genes. RT-PCR was performed using the primers Bc1g_14021-WT-F and Bc1g_14021-WT-R and cDNA derived from in planta material. The sequence data supported the proposed gene model. A replacement fragment for $b c 1 g \_14021$ was generated by the yeast recombination system and contains gene flanks of 0.524 and $1.113 \mathrm{~kb}$ and the hygromycin resistance cassette derived from pCSN44. For amplification of the flanks, primer pairs Bclg_14021-5F/-5R and Bclg_14021$3 \mathrm{~F} /-3 \mathrm{R}$ have been used (Fig. 3D). For transformation of $B$. cinerea $\mathrm{B} 05.10$, the replacement fragment was amplified using the primers Bclg_14021-5F and Bclg_14021-3R and the DNA of the respective yeast strain as template. $B$. cinerea transformants were analyzed by PCR for homologous integration of 
the replacement fragment (primer combinations Bclg_14021hi5F/pCSN44-hph-trpC-T and pCSN44-trpC-P/Bclg_14021hi3R) and for $B c l g \_14021$ alleles after single-spore isolations (primers Bclg_14021-WT-F and Bclg-14021-WT-R). For 7 of 11 hygromycin-resistant transformants, the homologous integration of the replacement fragments was proven. Homokaryotic lines of transformants T5 and T8 were generated by isolation of single conidia. For Southern analysis, genomic DNA of the mutants and the wild type was digested with PstI and hybridized to the $3^{\prime}$ flank. Due to an additional PstI site in the replacement fragment, the corresponding hybridizing fragment was $5.0 \mathrm{~kb}$ in the wild type and $2.5 \mathrm{~kb}$ in the mutants which have undergone homologous integration (Fig. 3D; data not shown).

\section{ACKNOWLEDGMENTS}

We thank B. Richter, D. Odinius, S. Ahrendt, and H. Conrad for excellent technical assistance; and B. Williamson for critically reading the manuscript.

\section{LITERATURE CITED}

Alonso, J. M., Stepanova, A. N., Leisse, T. J., Kim, C. J., Chen, H., Shinn, P., Stevenson, D. K., Zimmermann, J., Barajas, P., Cheuk, R., Gadrinab, C., Heller, C., Jeske, A., Koesema, E., Meyers, C. C., Parker, H., Prednis, L., Ansari, Y., Choy, N., Deen, H., Geralt, M., Hazari, N., Hom, E., Karnes, M., Mulholland, C., Ndubaku, R., Schmidt, I., Guzman, P., Aguilar-Hernonin, L., Schmid, M., Weigel, D., Carter, D. E., Marchand, T., Risseeuw, E., Brogden, D., Zeko, A., Crosby, W. L., Berry, C. C., and Ecker, J. R. 2003 Genome-wide insertional mutagenesis of Arabidopsis thaliana. Science 301:653-657.

Betts, M. F., Tucker, S. L., Galadima, N., Meng, Y., Patel, G., Li, L., Donofrio, N., Floyd, A., Nolin, S. Brown, D. Mandel, M. A., Mitchell, T. K., Xu, J.-R., Dean, R. A., Farman, M. L., and Orbach, M. J. 2007. Development of a high throughput transformation system for insertional mutagenesis in Magnaporthe oryzae. Fungal Genet. Biol. 44:10351049.

Blaise, F., Rémy, E., Meyer, M., Zhou, L., Narcy, J.-P., Roux, J., Balesdent, M.-H., and Rouxel, T. 2007. A critical assessment of Agrobacterium tumefaciens-mediated transformation as a tool for pathogenicity gene discovery in the phytopathogenic fungus Leptosphaeria maculans. Fungal Genet. Biol. 44:123-138.

Bundock, P., den Dulk-Ras, A., Beijersbergen, A., and Hooykaas, P. J. 1995. Trans-kingdom T-DNA transfer from Agrobacterium tumefaciens to Saccharomyces cerevisiae. EMBO (Eur. Mol. Biol. Organ.) J. 14:3206-3214.

Bundock, P., van Attikum, H., den Dulk-Ras, A., and Hooykaas, P. J. 2002. Insertional mutagenesis in yeasts using T-DNA from Agrobacterium tumefaciens. Yeast 19:529-536.

Cenis, J. L. 1992. Rapid extraction of fungal DNA for PCR amplification. Nucleic Acids Res. 20:2380.

Choi, J., Park, J., Jeon, J., Chi, M.-H., Goh, J. Yoo, S.-Y., Park, J., Jung, K., Kim, H., Park, S.-Y., Rho, H.-S., Kim, S., Kim, B. R., Han, S.-S., Kang, S., and Lee, Y.-H. 2007. Genome-wide analysis of T-DNA integration into the chromosomes of Magnaporthe oryzae. Mol. Microbiol. 66:371-382

Choi, Y. E., and Shim, W. B. 2008. Functional characterization of Fusarium verticillioides $\mathrm{CPP} 1$, a gene encoding a putative protein phosphatase 2A catalytic subunit. Microbiology 154:326-336.

Christianson, T. W., Sikorski, R. S., Dante, M., Shero, J. H., and Hieter, P. 1992. Multifunctional yeast high-copy-number shuttle vectors. Gene 110:119-122.

Colot, H. V., Park, G., Turner, G. E., Ringelberg, C., Crew, C. M., Litvinkova, L., Weiss, R. L., Borkovich, K. A., and Dunlap, J. C. 2006. A high-throughput gene knockout procedure for Neurospora reveals functions for multiple transcription factors. Proc. Natl. Acad. Sci. U.S.A. 103:10352-10357.

Covert, S. F., Kapoor, P., Lee, M., Briley, A., and Nairn, C. J. 2001. Agrobacterium tumefaciens-mediated transformation of Fusarium circinatum. Mycol. Res. 105:259-264.

de Groot, M. J., Bundock, P., Hooykaas, P. J., and Beijersbergen, A. G. 1998. Agrobacterium tumefaciens-mediated transformation of filamentous fungi. Nat. Biotechnol. 16:839-842.

Egan, J. D., García-Pedrajas, M. D., Andrews, D. L., and Gold, S. E. 2009. Calcineurin is an antagonist to PKA protein phosphorylation required for postmating filamentation and virulence, while PP2A is required for viability in Ustilago maydis. Mol. Plant-Microbe Interact. 22:12931301.

Erental, A., Harel, A., and Yarden, O. 2007. Type 2A phosphoprotein phosphatase is required for asexual development and pathogenesis of Sclerotinia sclerotiorum. Mol. Plant-Microbe Interact. 20:944-954.

Erental, A., Dickman, M. B., and Yarden, O. 2008. Sclerotial development in Sclerotinia sclerotioum: Awakening molecular analysis of a "Dormant" structure. Fungal Biol. Rev. 22:6-16.

Gupta, A., and Chattoo, B. B. 2008. Functional analysis of a novel ABC transporter ABC4 from Magnaporthe grisea. FEMS (Fed. Eur. Microbiol. Soc.) Microbiol. Lett. 278:22-28.

Harel, A., Bercovich, S., and Yarden, O. 2006. Calcineurin is required for sclerotial development and pathogenicity of Sclerotinia sclerotiorum in an oxalic acid-independent manner. Mol. Plant-Microbe Interact. 19:682-693.

Huisinga, K. L., and Pugh, B. F. 2004. A genome-wide housekeeping role for TFIID and a highly regulated stress-related role for SAGA in Saccharomyces cerevisiae. Mol. Cell 13:573-585.

Idnurm, A., and Howlett, B. J. 2001. Pathogenicity genes of phytopathogenic fungi. Mol. Plant Pathol. 2:241-255.

Idnurm, A., Reedy, J. L., Nussbaum, J. C., and Heitman, J. 2004. Cryptococcus neoformans virulence gene discovery through insertional mutagenesis. Eukaryot. Cell 3: 420-429.

Idnurm, A., Walton, F. J., Floyd, A., Reedy, J. L., and Heitman, J. 2009. Identification of ENA1 as a virulence gene of the human pathogenic fungus Cryptococcus neoformans through signature-tagged insertional mutagenesis. Eukaryot. Cell 8:315-326.

Jeon, J., Park, S.-Y., Chi, M.-H., Choi, J., Park, J., Rho, H.-S., Kim, S., Goh, J., Yoo, S., Choi, J., Park, J.-Y., Yi, M., Yang, S., Kwon, M.-J., Han, S.-S., Kim, B. R., Khang, C. H., Park, B., Lim, S.-E., Jung, K., Kong, S., Karunakaran, M., Oh, H.-S., Kim, H., Kim, S., Park, J., Kang, S., Choi, W.-B., Kang, S., and Lee, Y.-H. 2007. Genome-wide functional analysis of pathogenicity genes in the rice blast fungus. Nat. Genet. 39:561-565.

Laprade, L., Boyartchuk, V. L., Dietrich, W. F., and Winston, F. 2002. Spt3 plays opposite roles in filamentous growth in Saccharomyces cerevisiae and Candida albicans and is required for $C$. albicans virulence. Genetics 161:509-519.

Lazo, G. R., Stein, P. A., and Ludwig, R. A. 1991. A DNA transformationcompetent Arabidopsis genomic library in Agrobacterium. Biotechnology 9:963-967.

Lee, T. I., Causton, H. C., Holstege, F. C., Shen, W. C., Hannett, N., Jennings, E. G., Winston, F., Green, M. R., and Young, R. A. 2000 Redundant roles for the TFIID and SAGA complexes in global transcription. Nature 405:701-704.

Liu, Y.-G., and Whittier, R. F. 1995. Thermal asymmetric interlaced PCR: Automatable amplification and sequencing of insert end fragments form P1 and YAC clones for chromosome walking. Genomics 25:674-681.

Malonek, S., Rojas, M. C., Hedden, P., Gaskin, P., Hopkins, P., and Tudzynski, B. 2004. The NADPH:cytochrome P450 reductase gene from Gibberella fujikuroi is essential for gibberellin biosynthesis. J. Biol. Chem. 279:25075-25084.

Mattanovich, D., Rüker, F., Machado, A. C., Laimer, M., Regner, F., Steinkellner, H., Himmler, G., and Katinger, H. 1989. Efficient transformation of Agrobacterium spp. by electroporation. Nucleic Acids Res. 17:6747.

Meng, Y., Patel, G., Heist, M., Betts, M. F., Tucker, S. L., Galadima, N., Donofrio, N. M., Brown, D., Mitchell, T. K. Li, L., Xu, J.-R., Orbach, M., Thon, M., Dean, R. A., and Farman, M. L. 2007. A systematic analysis of T-DNA insertion events in Magnaporthe oryzae. Fungal Genet. Biol. 44:1050-1064.

Michielse, C. B., Hooykaas, P. J., van den Hondel, C. A., and Ram, A. F. 2005. Agrobacterium-mediated transformation as a tool for functional genomics in fungi. Curr. Genet. 48:1-17.

Michielse, C. B., Van Wijk, R., Reijnen, L., Cornelissen, B. J., and Rep, M. 2009. Insight into the molecular requirements for pathogenicity of Fusarium oxysporum f. sp. lycopersici through large-scale insertional mutagenesis. Genome Biol. 10:R4.

Münch, S., Ludwig, N., Floss, D. S., Sugui, J. A., Koszucka, A.M., Voll, L. M., Sonnewald, U., and Deising, H. B. 2011. Identification of virulence genes in the corn pathogen Colletotrichum graminicola by Agrobacterium tumefaciens-mediated transformation. Mol. Plant Pathol. 12:4355 .

Ochman, H., Gerber, A. S., and Hartl, D. L. 1988. Genetic applications of an inverse polymerase chain reaction. Genetics 120:621-623.

Ohmiya, R., Kato, C., Yamada, H., Aida, H., and Mizuno, T. 1999. A fission yeast gene $(\operatorname{prr} 1(+))$ that encodes a response regulator implicated in oxidative stress response. J. Biochem. 125:1061-1066.

Pontecorvo, G. V., Roper, J. A., Hemmons, L. M., MacDonald, K. D., and 
Bufton, A. W. J. 1953. The genetics of Aspergillus nidulans. Adv. Genet. 5:141-238.

Quidde, T., Osbourn, A. E., and Tudzynski, P. 1998. Detoxification of a-tomatine by Botrytis cinerea. Physiol. Mol. Plant. Pathol. 52:151-165.

Rolland, S., Jobic, C., Fèvre, M., and Bruel, C. 2003. Agrobacteriummediated transformation of Botrytis cinerea, simple purification of monokaryotic transformants and rapid conidia-based identification of the transfer-DNA host genomic DNA flanking sequences. Curr. Genet. 44:164-171.

Sambrook, J., Fritsch, E. F., and Maniatis, T. 1989. Molecular Cloning: A Laboratory Manual. Cold Spring Harbor Laboratory Press, Cold Spring Harbor, NY, U.S.A.

Schulze Gronover, C., Kasulke, D., Tudzynski, P., and Tudzynski, B. 2001 The role of $G$ protein alpha subunits in the infection process of the gray mold fungus Botrytis cinerea. Mol. Plant-Microbe Interact. 14:12931302.

Schumacher, J., de Larrinoa, I. F., and Tudzynski, B. 2008a. Calcineurinresponsive zinc finger transcription factor CRZ1 of Botrytis cinerea is required for growth, development, and full virulence on bean plants. Eukaryot. Cell. 7:584-601.

Schumacher, J., Viaud, M., Simon, A., and Tudzynski, B. 2008b. The Ga subunit BCG1, the phospholipase C (BcPLC1) and the calcineurin phosphatase co-ordinately regulate gene expression in the grey mould fungus Botrytis cinerea. Mol. Microbiol. 67:1027-1050.

Segmueller, N., Ellendorf, U., Tudzynski, B., and Tudzynski, P. 2007. $\mathrm{BcSAK} 1$, a stress-activated mitogen-activated protein kinase, is involved in vegetative differentiation and pathogenicity in Botrytis cinerea. Eukaryot. Cell 6:211-221.

Segmueller, N., Kokkelink, L., Giesbert, S., Odinius, D., van Kan, J. A. L., and Tudzynski, P. 2008. NADPH oxidases are involved in differentiation and pathogenicity in Botrytis cinerea. Mol. Plant-Microbe Interact. 21:808-819.

Singh, P., Chauhan, N., Ghosh, A., Dixon, F., and Calderone, R. 2004. SKN7 of Candida albicans: Mutant construction and phenotype analysis. Infect. Immun. 72:2390-2394.

Staben, C., Jensen, B., Singer, M., Pollock, J., Schechtman, M., Kinsey, J., and Selker, E. 1989. Use of a bacterial Hygromycin B resistance gene as a dominant selectable marker in Neurospora crassa transformation. Fungal Genet. Newsl. 36:79-81.

Temme, N., and Tudzynski, P. 2009. Does Botrytis cinerea ignore $\mathrm{H}_{2} \mathrm{O}_{2}$ induced oxidative stress during infection? Characterization of Botrytis activator protein 1. Mol. Plant-Microbe Interact. 22:987-998.

Terauchi, R., and Kahl, G. 2000. Rapid isolation of promotor sequences by TAIL-PCR: The 5'-flanking regions of $\mathrm{Pal}$ and $\mathrm{Pgi}$ genes form yams (Dioscorea). Mol. Gen. Genet. 263:554-560.

Tudzynski, P., and Kokkelink, L. 2009. Botrytis cinerea: Molecular aspects of a necrotrophic life style. Pages 29-50 in: Plant Relationships V, 2nd ed. H. B. Deising, ed. Springer-Verlag, Berlin, Heidelberg, Germany.

Tudzynski, P., and Siewers, V. 2004. Approaches to molecular genetics and genomics of Botrytis. Pages 53-66 in: Botrytis: Biology, Pathology and Control. Y. Elad, B. Williamson, P. Tudzynski, and N. Delen, eds. Kluwer Academic Press, Dordrecht, The Netherlands.

van Kan, J. A. L. 2006. Licensed to kill: The lifestyle of a necrotrophic plant pathogen. TIPS 11:247-253.

Viaud, M., Brunet-Simon, A., Brygoo, Y., Pradier, J. M., and Levis, C. 2003. Cyclophilin A and calcineurin functions investigated by gene inactivation, cyclosporin A inhibition and cDNA arrays approaches in the phytopathogenic fungus Botrytis cinerea. Mol. Microbiol. 50:14511465 .

Viaud, M., Legeai, F., Pradier, J. M., Brygoo, Y., Bitton, F., Weissenbach, J., Brunet-Simon, A., Duclert, A., Fillinger, S. Fortini, D., Gioti, A., Giraud, C. Halary, S., Lebrun, I., Le Pecheur, P., Samson, D., and Levis, C. 2005. Expressed sequence tags from the phytopathogenic fungus Botrytis cinerea. Eur. J. Plant Pathol. 111:139-146.

Walton, F. J., Idnurm, A., and Heitman, J. 2005. Novel gene functions required for melanization of the human pathogen Cryptococcus neofor mans. Mol. Microbiol. 57:1381-1396.

Williams, K. E., and Cyert, M. S. 2001. The eukaryotic response regulator Skn7p regulates calcineurin signaling through stabilization of Crzlp. EMBO (Eur. Mol. Biol. Organ.) J. 20:3473-3483.

Williamson, B., Tudzynski, B., Tudzynski, P., and van Kan J. A. L. 2007. Botrytis cinerea: The cause of grey mould disease. Mol. Plant Pathol. 8:561-580.

Winston, F., Dollard, C., and Ricupero-Hovasse, S. L. 1995. Construction of a set of convenient Saccharomyces cerevisiae strains that are isogenic to S288C. Yeast 11:53-55.

Wormley, F. L., Jr., Heinrich, G., Miller, J. L., Perfect, J. R., and Cox, G. M. 2005. Identification and characterization of an SKN7 homologue in Cryptococcus neoformans. Infect. Immun. 73:5022-5030.

Yang, Y., He, Q., Cheng, P., Wrage, P., Yarden, O., and Liu, Y. 2004. Distinct roles for PP1 and PP2A in the Neurospora circadian clock. Genes Dev. 18:255-260.

Yatzkan, E., and Yarden, O. 1995. Inactivation of a single-2A phosphoprotein phosphatase is lethal in Neurospora crassa. Curr. Genet. 28:458 466.

\section{AUTHOR-RECOMMENDED INTERNET RESOURCES}

Botrytis cinerea database: www.broadinstitute.org/annotation/genome/botrytis_cinerea

Broad Institute Sclerotinia sclerotiorum database: www.broadinstitute.org/annotation/genome/sclerotinia_sclerotiorum

INRA's URGI Plant and Fungi Data Inegration Botrytis cinerea genome project webpage: urgi.versailles.inra.fr/Species/Botrytis/

National Center for Biotechnology Information BLASTN and BLASTX database: www.ncbi.nlm.nih.gov/BLAST

Sanger Institute PFAM database: pfam.sanger.ac.uk/search 